\title{
Thermomechanical behaviour of refractory dry-stacked masonry walls under uniaxial compression
}

\author{
Rafael L. G. Oliveira ${ }^{1}$; João Paulo C. Rodrigues ${ }^{1}$; João M. Pereira²; Paulo B. Lourençoº ${ }^{2}$ Hans Ulrich \\ Marschall ${ }^{3}$ \\ ${ }^{1}$ University of Coimbra, Faculty of Sciences and Technology, Portugal \\ ${ }^{2}$ University of Minho, School of Engineering, ISISE - Institute for Sustainability and Innovation in \\ Structural Engineering, Portugal \\ ${ }^{3}$ RHI Magnesita, Technology Center Leoben, 8700 Leoben, Austria
}

\begin{abstract}
The vessels used in industrial high temperature processes of steel and cement production are protected by refractory linings built with dry-stacked masonry, which plays a crucial role on the overall behaviour of the vessels. This paper presents the results of an experimental and numerical research on dry-joint refractory masonry under uniaxial compression. Its main purpose is to fully characterize the masonry walls at different temperatures and different loading conditions. Several aspects that may influence the behaviour of these walls have been tested, namely the loadbearing capacity, the behaviour under cyclic loading and the restrained thermal elongation. The experimental results allowed to identify the effects of the stresses concentrations caused by brick's height imperfections in the mechanical behaviour of the bricks and in the loadbearing capacity of specimens, the evolution of the wall's Young's modulus with the load application, the developed crack patterns and the mechanical behaviour of the samples under room and elevated temperatures. Numerical models were also developed to simulate the behaviour of the walls under different testing conditions and a good agreement with the experimental results was obtained. The concrete damaged plasticity model, using a micro-modelling approach, proved to be suitable for representing the behaviour of these walls at ambient and high temperatures.
\end{abstract}

Keywords: refractory; masonry walls; ambient and high temperatures; thermomechanical modelling; drystacked masonry. 


\section{Introduction}

The industrial vessels used in high temperature processes, such as steel ladles and cement rotary kilns, are protected by refractory linings. The linings shall perform different functions, including protection of the industrial equipment, safety of personnel, confinement of the solid, liquid and gases in the containers and a contribution to limit heat loses [1]. The service temperatures of the vessels may reach $1650^{\circ} \mathrm{C}$ for the steel ladles and $1450{ }^{\circ} \mathrm{C}$ for the cement kilns [1,2]. Besides the high temperatures, other actions may influence the thermomechanical behaviour of the linings, such as mechanical stresses, abrasion, creep, thermal shock and corrosion. The working lining of these vessels are usually built with dry-joint masonry [2-7].

The thermal gradients through the thickness of the linings, together with the different thermal elongation of the refractory layers and the steel shells, lead to significant compressive stresses in the linings. The developed stresses may result in failure of the linings or induce creep [8-10]. The dry joints formed between the stacked bricks have a small thickness, however, they play an important role on reducing the stresses generated in the linings. In dry-stacked masonry, two geometric imperfections are of paramount importance: imperfections in height between different bricks $(\Delta \mathrm{H})$ and the roughness of the bricks' surface $(\Delta \mathrm{h})$ [11-12].

Thanoon et al [13] proposed a mathematical model to describe the nonlinear compressive stresses in dry-joint masonry in terms of joint closure $\left(d_{n}\right)$ and constants obtained experimentally ( $a, b$ and $c$ ), as shown in Eq. 1. The normal tangent stiffness of the joint, $k_{n}$, increases with the load level and it may be obtained by differentiating Eq. 1 in terms of $d_{n}$, as shown in Eq. 2. These equations might be used to represent the normal behaviour of the joint in numerical models.

$$
\begin{aligned}
& \sigma_{n}=a d_{n}^{b}+c d_{n} \\
& k_{n}=a b d_{n}^{b-1}+c
\end{aligned}
$$

Gasser et al [6] performed an experimental study on the behaviour of refractory brick's dry joints. The forcedisplacement curve obtained experimentally on a compressive test in two stacked bricks (in the low range of normal load when compared to the failure load) presented different stages: $i$ ) first, a non-linear part corresponding to the joint closure; and ii) second, a linear part corresponding to the brick elastic behaviour. 
The joint thickness may be estimated from this curve. Andreev et al [14] extended this research, performing compressive tests in prisms formed by magnesia-carbon and magnesia-chromite bricks in a wide temperature range. These authors highlighted that the exponential form of the joint closure curve is a result of the gradual crushing of initially non-parallel surfaces. The tests were also performed at high temperatures and it was observed that the temperature influences the joint closure by changing the stiffness of the material and reducing the initial gap. The contact area between the bricks was found to be proportional to the applied stress. The authors observed that the joint thickness is not constant along the joint due to surface roughness, bricks' shape variations and non-parallelism of faces. Allaoui et al [3] further expanded these previous studies. The authors evaluated the roughness of the bricks' surface and found that the arithmetical mean roughness was about $12 \pm 2 \mu \mathrm{m}$, which indicates that the joint behaviour is caused mainly by the lack of planarity of the brick surfaces. These authors highlighted that the process of joint closure involves roughness crushing and adjustment of surfaces, which is a strongly heterogeneous, orthotropic and nonlinear process. In one specimen, the authors observed local joint opening during the first stage of the test, caused by rigid body motion that induced rotation of the contacting bricks.

The effects of the contact surface unevenness on the behaviour of dry-stacked masonry at room temperature was evaluated by Zahra et al [12]. The authors used matrix based tactile surface sensors (MBTSS) to determine the contact pressure at the interface of concrete bricks. Several high-pressure points were obtained, mostly caused by the presence of random interstices and coarse aggregates in the blocks' surface. Ngapeya et al [11] evaluated the effects of bricks' height imperfection on the behaviour of this type of masonry. These imperfections led to an uneven stress distribution in the wall, resulting in significant stress concentrations. To study this effect, the authors developed numerical models and considered five loading cases for a singular brick varying its support and loading conditions. The uneven stress distribution in the wall resulted in a significant reduction of its loadbearing capacity.

Despite the extensive literature available about the thermomechanical behaviour of masonry in case of fire [15-27], there is still a gap in literature regarding refractory masonry. Prietl et al [28-29] developed a dedicated device for testing refractory masonry walls under biaxial compression. The experimental setup allowed 
characterizing refractory masonry at ambient and high temperatures. These authors performed a large experimental testing campaign on masonry walls under uniaxial and biaxial loading conditions, which allowed calibration and validation of numerical models $[5,30]$.

Due to the current lack of knowledge on the behaviour of dry-joint refractory masonry, this study aims to investigate the thermomechanical behaviour of this material. Several tests have been carried out at ambient temperature to assess the loadbearing capacity of dry-joint refractory masonry and its behaviour under cyclic loading. In addition, tests at high temperatures were carried out to evaluate the behaviour of this masonry under diverse loading conditions. Finally, a numerical study was performed to further discuss the results of the experimental programme.

\section{Experimental tests}

This section presents the experimental programme carried out to assess the loadbearing capacity at ambient and high temperatures of walls made with refractory masonry, their response under cyclic loading and their mechanical behaviour under constant loading or restrained thermal elongation. The experimental tests were carried out at the Laboratory of Testing Materials of the University of Coimbra, in Portugal.

\subsection{Materials}

Alumina-spinel bricks were used within this work. These are being increasingly applied in vessels for steel industry applications, especially in the working lining of steel ladles [1]. The dimensions of the bricks were 150x140x $100 \mathrm{~mm}$ and the dimensions of half-bricks also used were $(75 \times 140 \times 100 \mathrm{~mm})$. The material chemical composition, measured according to EN ISO 12677 [31] is presented in Table 1.

Table 1 - Chemical composition of alumina-spinel bricks according to EN ISO 12677

\begin{tabular}{cccc}
\hline $\mathrm{Al}_{2} \mathrm{O}_{3}$ & $\mathrm{Fe}_{2} \mathrm{O}_{3}$ & $\mathrm{SiO}_{2}$ & $\mathrm{MgO}$ \\
\hline $94.0 \%$ & $0.1 \%$ & $0.3 \%$ & $5.0 \%$ \\
\hline \multicolumn{2}{l}{ Determination on fired substance $\left(1025^{\circ} \mathrm{C} / 1877^{\circ} \mathrm{F}\right)$} \\
\hline
\end{tabular}

The alumina-spinel brick was fully characterized within the scope of the ATHOR Project [9,10,33-36], a training network dedicated to thermomechanical multiscale modelling of refractory linings. The brick's 
density is $3.13 \mathrm{~g} / \mathrm{cm}^{3}$ and its apparent porosity measured according to EN 993-1 [32] is 19\%. The compressive strength [33] and the tensile strength [34] are presented in Figure 1 for different temperatures. The characterization of the material in compression was performed at room temperature, $800{ }^{\circ} \mathrm{C}$ and $1000{ }^{\circ} \mathrm{C}$. In the numerical studies, the material behaviour was assumed to be linear between these points. The variation of the Young's modulus with the temperature (measured by ultrasonic pulse velocity tests [34]) is presented in

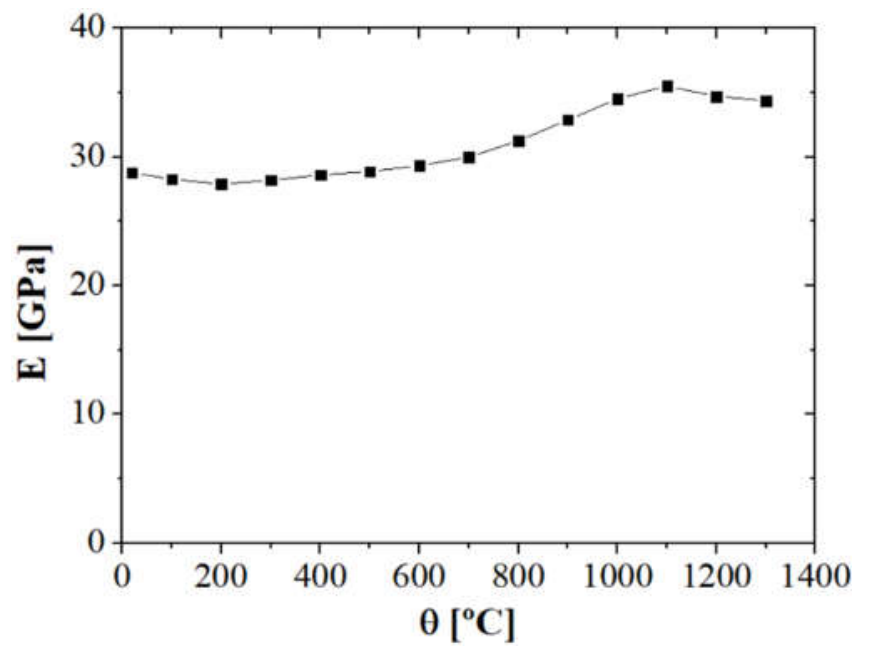

Figure 2. The expansion coefficient of the materials is $8.59 \times 10^{-6} /{ }^{\circ} \mathrm{C}[34]$.

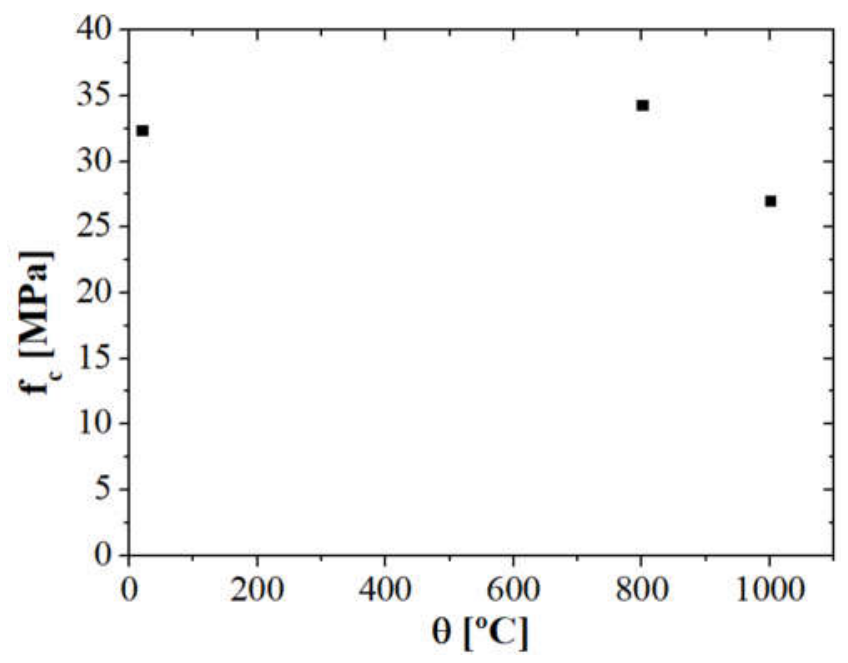

a)

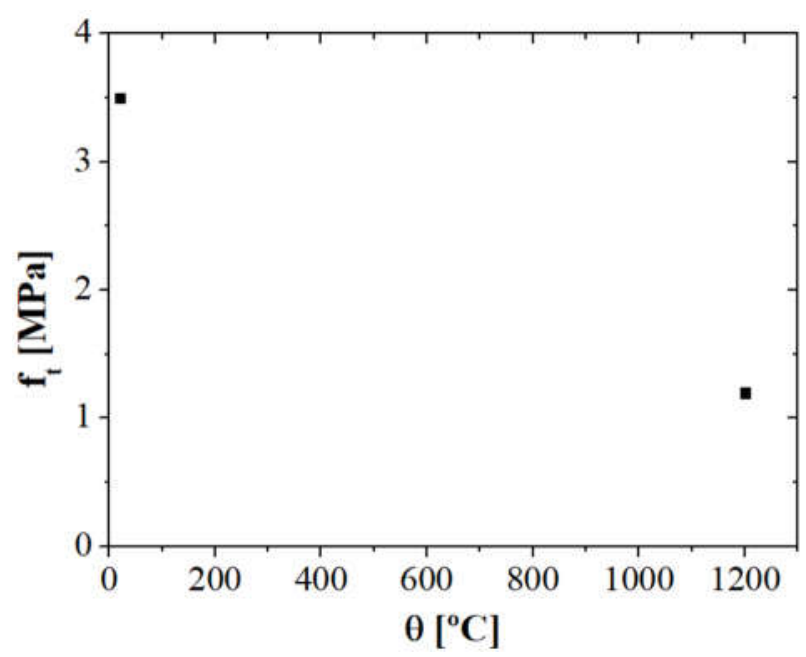

b)

Figure 1 - Mechanical properties of alumina spinel: a) Compressive strength [33]; b) Tensile strength [34] 


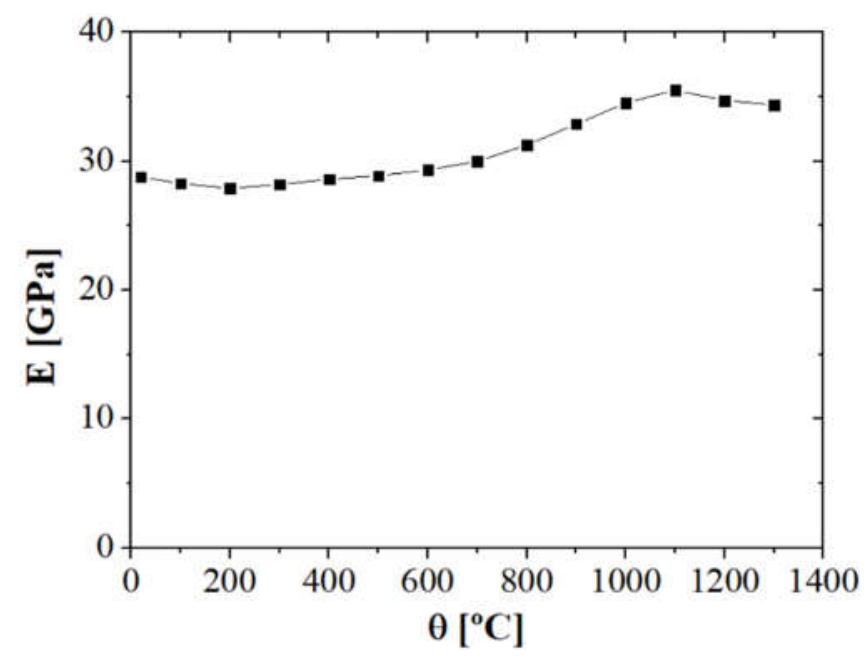

Figure 2 - Alumina spinel Young's modulus [34]

The brick's shapes imperfections play an important role on the behaviour of dry-joints masonry [3, $6,11,12$, 14]. The imperfections are defined by the differences between the measured and the design dimensions. In the directions perpendicular to the pressing, the imperfections vary from $-1.1 \mathrm{~mm}$ up to $+0.8 \mathrm{~mm}$, in agreement with the tolerances indicated by the supplier $( \pm 1.0 \mathrm{~mm})$, with a standard deviation of $0.41 \mathrm{~mm}$. In the direction of pressing, the supplier indicated tolerances are higher $( \pm 2.0 \mathrm{~mm})$ and higher imperfections were indeed observed, ranging from $-2.4 \mathrm{~mm}$ up to $+1.4 \mathrm{~mm}$, with a standard deviation of $0.84 \mathrm{~mm}$. The deviations in the pressing direction are highly influenced by the applied pressure and the amount of material injected in the moulds. Consequently, higher deviations are found.

\subsection{Experimental programme}

The experimental programme comprised fourteen tests divided in five series (Table 2):

Series S01.AT.LBC: carried out at ambient temperature (AT) aiming to assess the loadbearing capacity (LBC) of the wall.

Series S02.AT.CIC: carried out at ambient temperature (AT) aiming to assess the behaviour of the masonry under cyclic loads (CIC).

Series S03.HT.LL8: carried out at high temperatures (HT) aiming to assess the thermomechanical behaviour of the masonry under a constant load level (LL8). Firstly, a mechanical load of 8 MPa was applied to the specimen, then the wall is heated according to ISO 834-1 [37]. 
Series S04.HT.RTE: tested at high temperatures (HT) aiming to assess the behaviour of masonry under restrained thermal elongation (RTE). First, a mechanical load of $5 \mathrm{MPa}$ was applied to the specimen, then the hydraulic jack is blocked at its current position and the specimen is heated according to the ISO 834-1 [37].

Series S05.HT.LL10: carried out at high temperatures (HT) aiming to assess the thermomechanical behaviour of the masonry wall with higher slenderness ratio under a constant load level(LL10). Firstly, a mechanical load of $10 \mathrm{MPa}$ is applied to the specimen, then the wall is heated according to ISO 834$1[37]$. 
Table 2 - Test series

\begin{tabular}{|c|c|c|c|c|c|c|}
\hline Series & Test Number & $\begin{array}{c}\text { Temperature } \\
\text { of the test }\end{array}$ & Thermal restraining & $\begin{array}{l}\text { Type of } \\
\text { control }\end{array}$ & Maximum load & Cycles \\
\hline \multirow{3}{*}{ S01.AT.LBC } & S01.AT.LBC.01 & \multirow{6}{*}{$\begin{array}{l}\text { Ambient } \\
\text { temperature }\end{array}$} & \multirow{6}{*}{ None } & \multirow{3}{*}{ Displacement } & \multirow{3}{*}{ Up to failure } & \multirow{3}{*}{-} \\
\hline & S01.AT.LBC.02 & & & & & \\
\hline & S01.AT.LBC.03 & & & & & \\
\hline \multirow{3}{*}{ S02.AT.CIC } & S02.AT.CIC.01 & & & \multirow{3}{*}{ Displacement } & \multirow{3}{*}{$1,2,5$ and $8 \mathrm{MPa}$} & \multirow{3}{*}{4} \\
\hline & S02.AT.CIC.02 & & & & & \\
\hline & S02.AT.CIC.03 & & & & & \\
\hline \multirow{3}{*}{ S03.HT.LL8 } & S03.HT.LL8.01 & \multirow{8}{*}{$\begin{array}{c}\text { High } \\
\text { temperatures }\end{array}$} & \multirow{3}{*}{$\begin{array}{c}\text { Constant loading and } \\
\text { no thermal } \\
\text { restraining }\end{array}$} & \multirow{3}{*}{ Load } & \multirow{3}{*}{$8 \mathrm{MPa}$} & \multirow{3}{*}{-} \\
\hline & S03.HT.LL8.02 & & & & & \\
\hline & S03.HT.LL8.03 & & & & & \\
\hline \multirow{3}{*}{ S04.HT.RTE } & S04.HT.RTE.01 & & \multirow{3}{*}{ Thermal restraining } & \multirow{3}{*}{ Displacement } & \multirow{3}{*}{$\begin{array}{l}\text { Pre-load: } 5 \mathrm{MPa} \\
\text { + Effects of } \\
\text { restrained thermal } \\
\text { elongation }\end{array}$} & \multirow{3}{*}{-} \\
\hline & S04.HT.RTE.02 & & & & & \\
\hline & S04.HT.RTE.03 & & & & & \\
\hline \multirow[b]{2}{*}{ S05.HT.LL10 } & S05.HT.LL10.01 & & \multirow{2}{*}{$\begin{array}{c}\text { Constant loading and } \\
\text { no thermal } \\
\text { restraining }\end{array}$} & \multirow[b]{2}{*}{ Load } & \multirow[b]{2}{*}{$10 \mathrm{MPa}$} & \multirow[b]{2}{*}{-} \\
\hline & S05.HT.LL10.02 & & & & & \\
\hline
\end{tabular}

\subsection{Test specimens}

The specimens consisted of dry-stacked masonry walls made of high-alumina bricks. The properties of the material and the dimensions of the bricks were described in section 2.1. In order to fully characterize the masonry thermomechanical behaviour, three different configurations were used in the tests. Figure 3 presents the general arrangement of the specimens. The choice of the thickness for S01 to S04 (140 mm) was based on the usual thickness of the working lining of steel ladles. For S05, a smaller thickness (100 mm) was used aiming to increase the slenderness of the wall. The length of the wall for series S01 $(450 \mathrm{~mm})$ was chosen based on the structural capacity of the loading frame and the maximum capacity of the hydraulic jack, as this series aims to assess the loadbearing capacity of the wall. The length of the specimens used in S02 to S05 (1350 mm) was chosen based on the dimensions of the electric furnace used. 


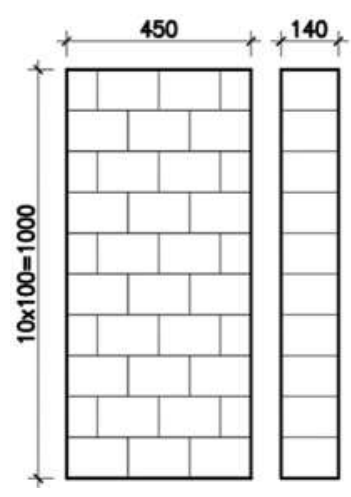

a)

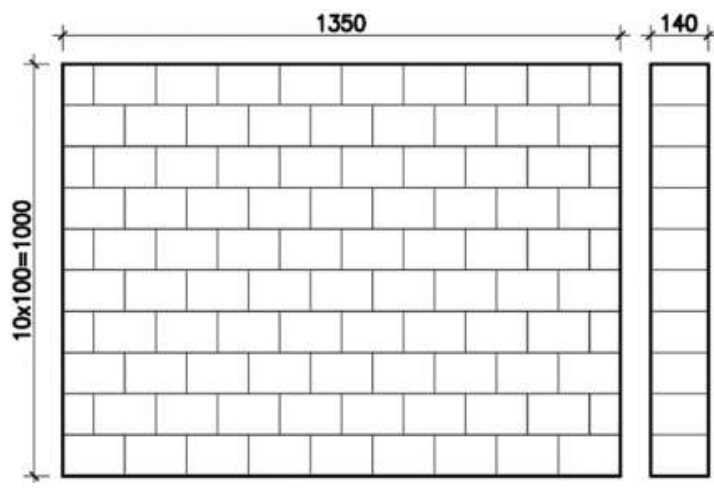

b)

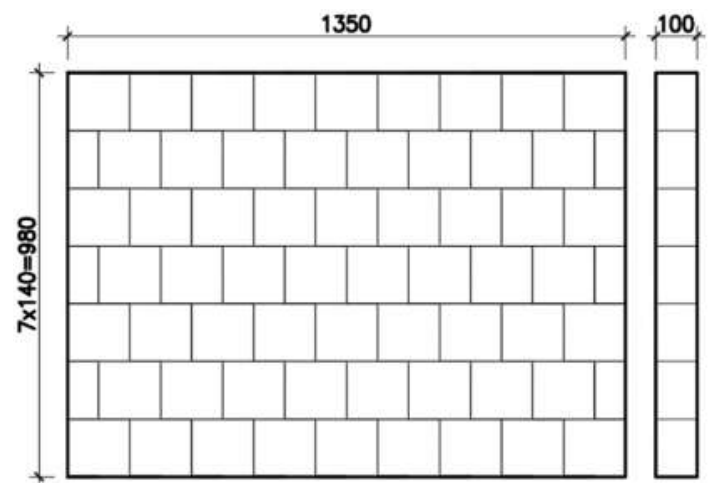

Dimensions in $\mathrm{mm}$

Figure 3 - Specimens dimensions: a) Series S01; b) Series S02, S03 and S04; c) Series S05

\subsection{Test set-up}

A schematic view of the experimental set-up used is presented in Figure 4. The set-up consisted of one reaction frame (two HEB500 columns and two HEB600 beams), one hydraulic jack to apply the load (up to $3 \mathrm{MN}$ ), one load cell to measure the applied load (up to $5 \mathrm{MN}$ ) and one modular electric furnace ( $45 \mathrm{kVA}$ ) to heat the specimens. A hydraulic jack applied a load in the plane of the wall by two load beams. The top beam was a steel beam (HEB240) and the bottom beam was a composite beam (tubular steel section filled with concrete). The verticality of the wall was ensured by two lateral steel frames. The hydraulic jack was controlled by a servo hydraulic central unit W+B NSPA700/DIG2000. Two masonry columns were built at the edges of the specimens to limit heat loses.

The reaction frame was bolted to the laboratory slab by steel anchors. The specimens were built in the reaction slab over a grout layer. Rockwool was used for the thermal insulation of the reaction slab and to fill the gap between the specimens and the lateral masonry columns. The pictures of the experimental set-up are presented in Figure 5a and Figure 5b for the tests at ambient and high temperatures, respectively. 


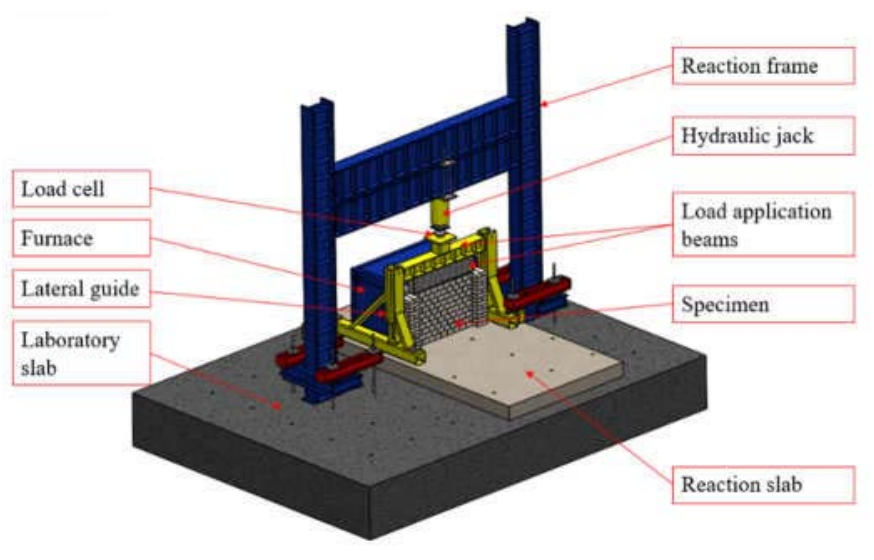

a)

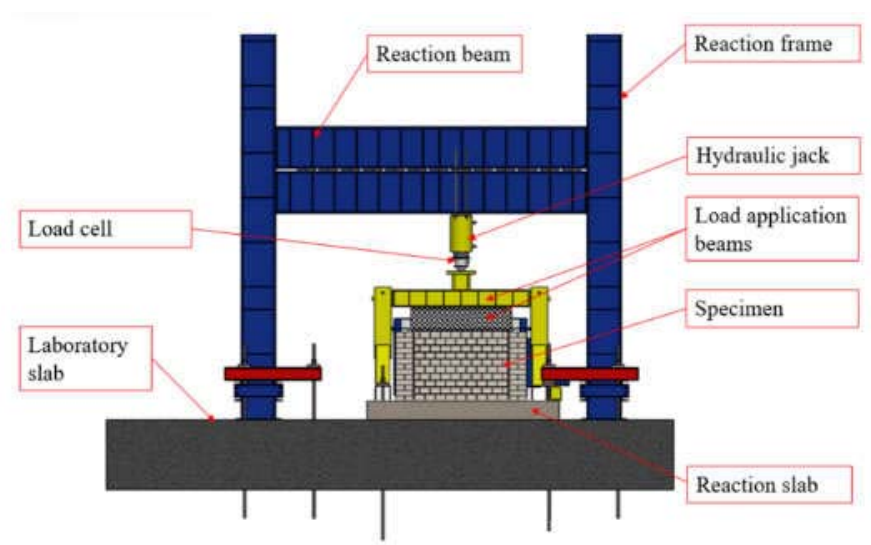

b)

Figure 4 - Test set-up: a) Isometric view; b) Front view

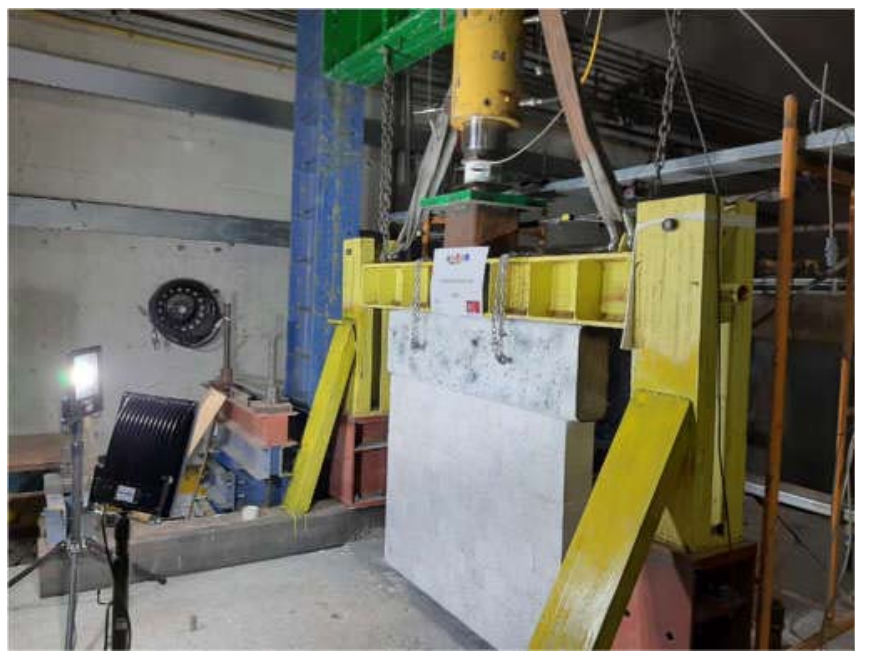

a)

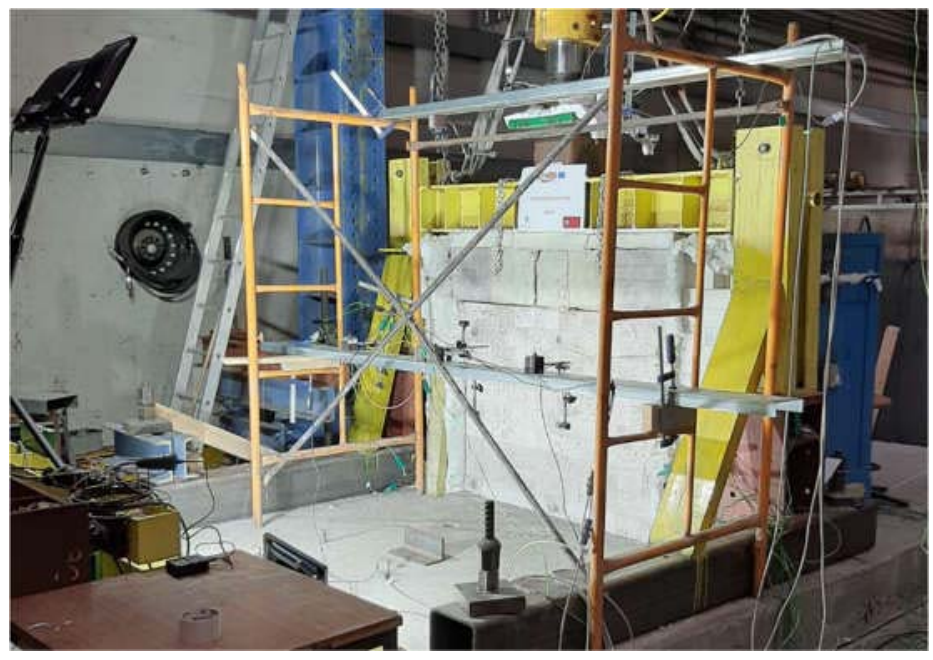

b)

Figure 5 - Test set-up: a) Ambient temperatures; b) High temperatures

The load cell used to measure the loading applied to the specimen was placed between the hydraulic jack's head and the loading beams (Figure 4). Three LVDTs placed at the top of the loading beam were used to measure the in-plane displacements (LVDT-IP). Five LVDTs were used to measure the out-of-plane displacements (LVDT-OoP). The position of the LVDTs are detailed in Figure 6. 


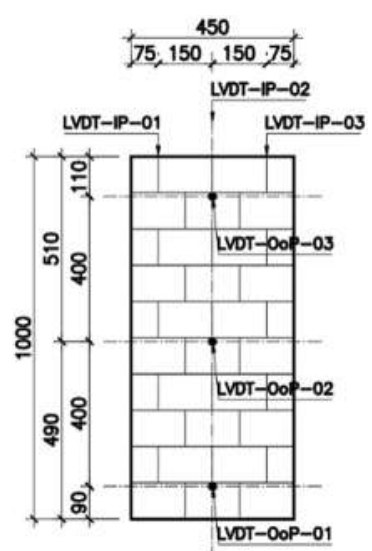

a)

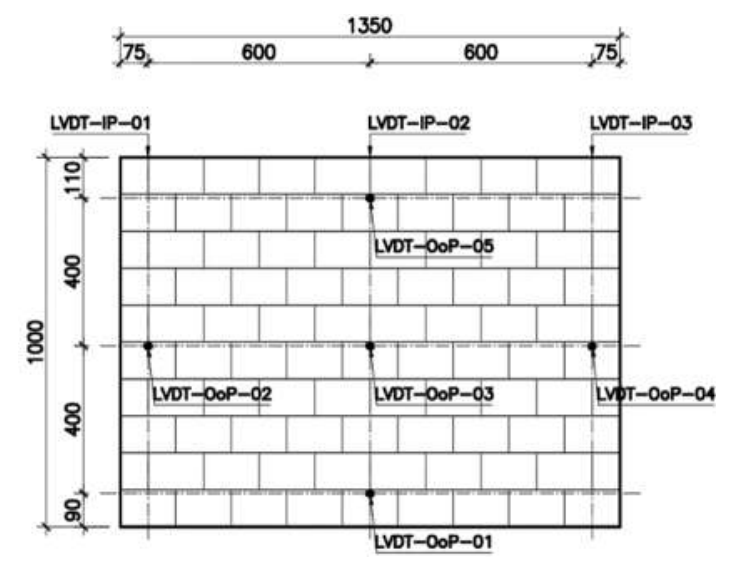

b)

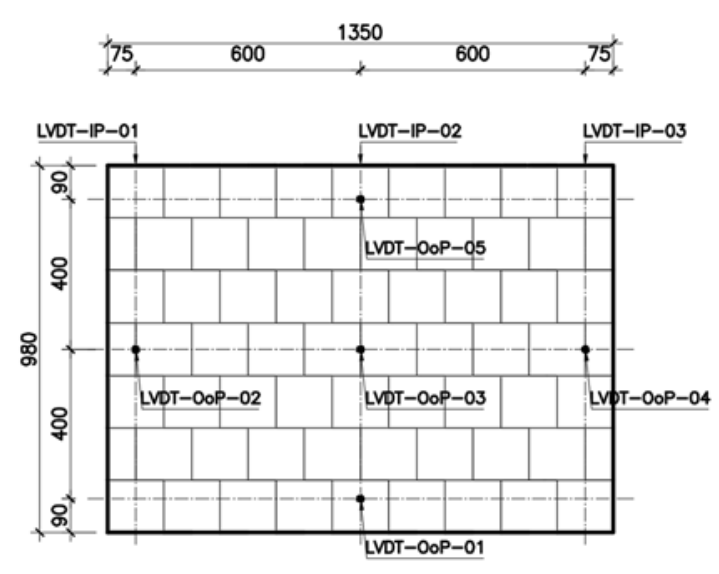

Measures in $\mathrm{mm}$

c)

Figure 6 - Test LVDTs instrumentation: a) Series S01; b) Series S02, S03 and S04; c) Series S05

Digital image correlation (DIC), which is a contactless measurement technique, was used to measure the fullfield of displacements and strains. This technique was developed in the beginning of the 1980's and improved over the time. The basic principle is to compare two images that represent different states of the specimen, a reference and a deformed condition. The technique assumes that the grey level distribution follows the material strains and remains homogenous in the subset $[38,39]$. An $18 \mathrm{MPx}(5184 \times 3486)$ camera was used for image acquisition. The bricks were laid on a horizontal plane and the speckle pattern was applied by means of an aerograph. The speckle pattern application and its details are shown in Figure 7. The image processing was performed using subsets of 100x100 pixels. The technique was used to measure the strains in all the tests.

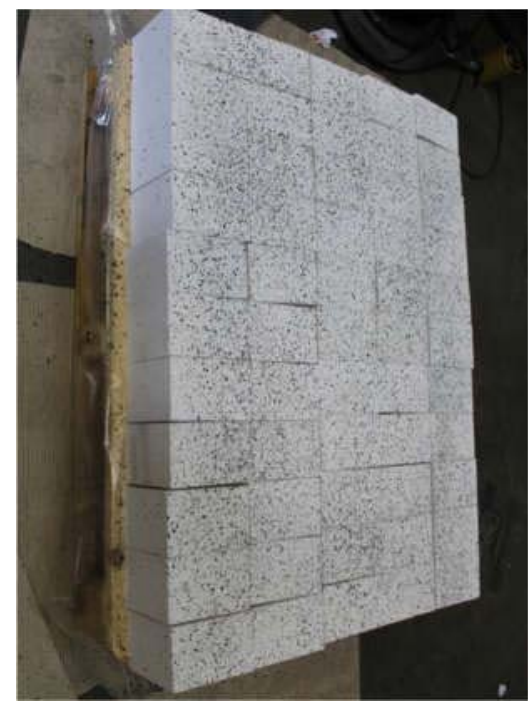

a)

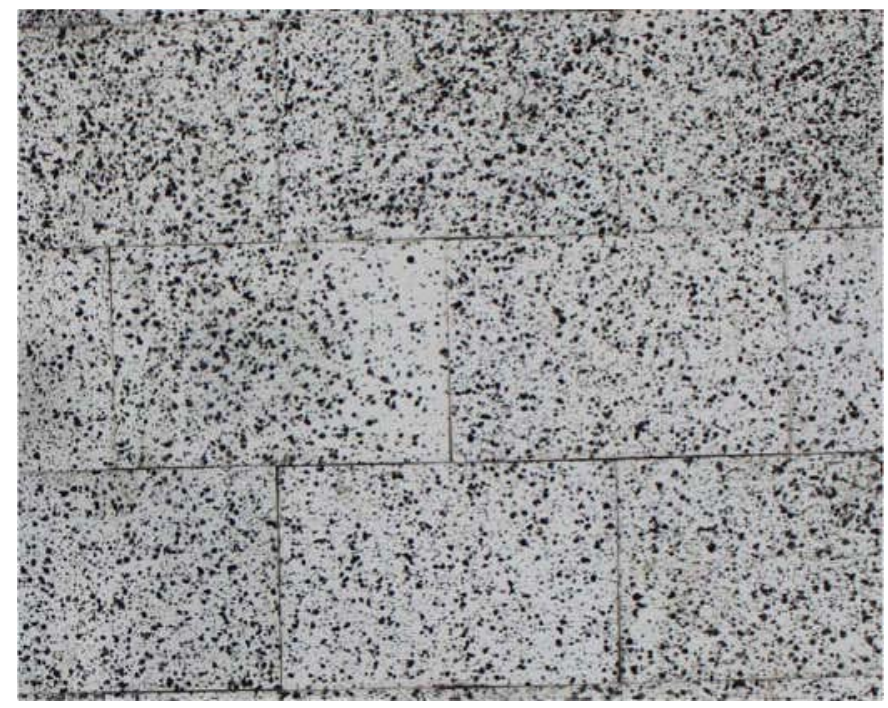

b)

Figure 7 - Digital Image Correlation: a) Speckle pattern preparation; b) Details of the speckle pattern 
The thermal instrumentation comprised eighteen type $\mathrm{K}$ thermocouples embedded in the bricks $(10 \mathrm{~mm}$ depth), nine installed in the hot face and nine in the cold face, as detailed in Figure 8. The holes (ø6 mm) were made in the bricks using diamond crown drills. Subsequently, the thermocouples were placed in the holes and grout was used to close them. Additionally, one type K thermocouple was used in the furnace controller and one type $\mathrm{K}$ thermocouple was used to record the temperature in the furnace.

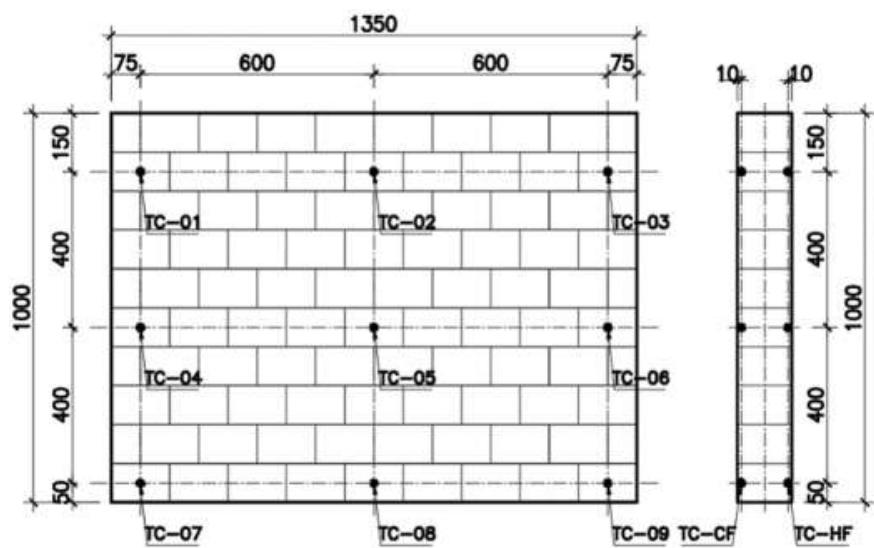

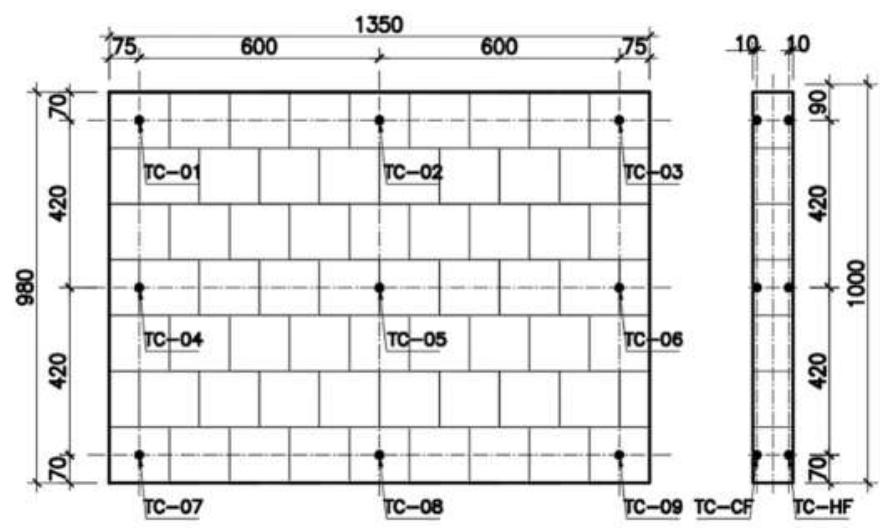

Measures in $\mathrm{mm}$

a)

b)

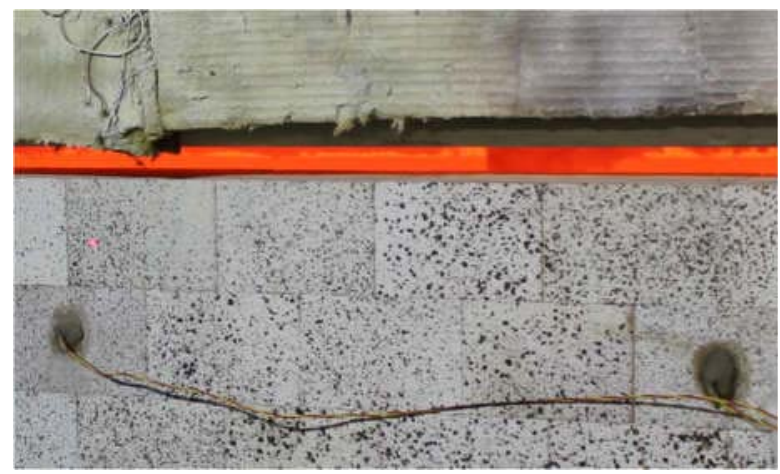

c)

Figure 8 - Thermal instrumentation: a) Series S03 and S04; b) Series S05; c) View of thermocouples embedded in the bricks

\subsection{Test procedure}

The test procedure used in each test series was the following:

- Test series S01.AT.LBC: The objective of test series S01.AT.LBC was to assess the loadbearing capacity of the refractory masonry walls. The test procedure in series S01.AT.LBC had the following steps: $i$ ) the masonry specimens were built in the testing frame; $i$ ) the loading beams were placed on the top of the specimens using a crane; iii) the instrumentation was installed; $i v$ ) the loadbearing 
capacity test was performed under displacement control at the rate of $0.01 \mathrm{~mm} / \mathrm{s}$ up to failure of the specimen.

- Test series S02.AT.CIC: The objective of test series S02.AT.CIC was to assess the behaviour of refractory masonry under cyclic loading. Steps $i$, ii and iii of this test procedure were similar to the ones presented for series S01.AT.LBC. Then: $i v$ ) the test was performed under displacement control at a rate of $0.01 \mathrm{~mm} / \mathrm{s} ; \mathrm{v}$ ) the wall was submitted to four loading and unloading cycles with increasing load, to the following stress levels: 1,2, 5 and $8 \mathrm{MPa}$. The specimen was not tested up to the failure.

- Test series S03.HT.LL8: Series S03.HT.LL8 was tested at high temperatures. Steps $i$, ii and iii of the test procedure were similar to the ones presented for series S01.AT.LBC. Then: $i v$ ) the specimen was loaded under displacement control at the rate of $0.01 \mathrm{~mm} / \mathrm{s}$ up to $8 \mathrm{MPa}$ at ambient temperature, $v$ ) the control procedure was changed to load control and set to keep the current load; vi) the furnace was turned on and the specimen was heated according to the standard fire curve ISO 834-1 [37]; vii) the wall was monitored for five hours. The specimen was not tested up to the failure.

- Test series S04.HT.RTE: The objective of series S04.HT.RTE was to assess the mechanical behaviour of refractory masonry walls subjected to restrained thermal elongation. Steps $i, i i$ and $i i i$ of the test procedure were similar to the ones presented for series S01.AT.LBC. Then: $i v$ ) the specimen was loaded under displacement control at the rate of $0.01 \mathrm{~mm} / \mathrm{s}$ up to $5 \mathrm{MPa} ; v$ ) the hydraulic jack was fixed at its current position; vi) the furnace was turned on and the specimen was heated according to the standard fire curve ISO 8341-1 [37]; vii) the wall was monitored for five hours. The specimen was not tested up to the failure.

- Test series S05.HT.LL10: The objective of series S05.HT.LL10 was to assess the mechanical behaviour of refractory masonry wall subject to constant load (10 $\mathrm{MPa})$ under increasing temperature. Steps $i, i i$ and $i i i$ of the test procedure were similar to the ones presented for series S01.AT.LBC. Then: $i v)$ the specimen was loaded under displacement control at the rate of $0.01 \mathrm{~mm} / \mathrm{s}$ up to $10 \mathrm{MPa}$ at ambient temperature, $v$ ) the control procedure was change to load control and set to keep the current 
load; vi) the furnace was turned on and the specimen was heated according to the standard fire curve ISO 834-1 [37]; vii) the wall was monitored for five hours. Failure occurred to the combined stress level and temperature increase.

\section{Results of the experimental tests and discussion}

\subsection{Test series S01.AT.LBC}

The stress-strain curves of test series S01.AT.LBC are presented in Figure 9. The strains were calculated using the mean displacement of the three LVDTs divided by the height of the specimen. Three different stages were observed: $i$ ) joint closure; ii) linear behaviour; iii) damage plasticity and failure. During stage $i$, the Young's modulus of the wall increased from almost zero up to $6.2 \mathrm{GPa}$. In this stage crushing of brick's initial nonplane surfaces occurs $[3,6,14]$. The joint closure behaviour is strongly heterogeneous along the joints as it is influenced by the bricks shape imperfections, bricks surface roughness and construction errors $[3,6,11,12,14]$.

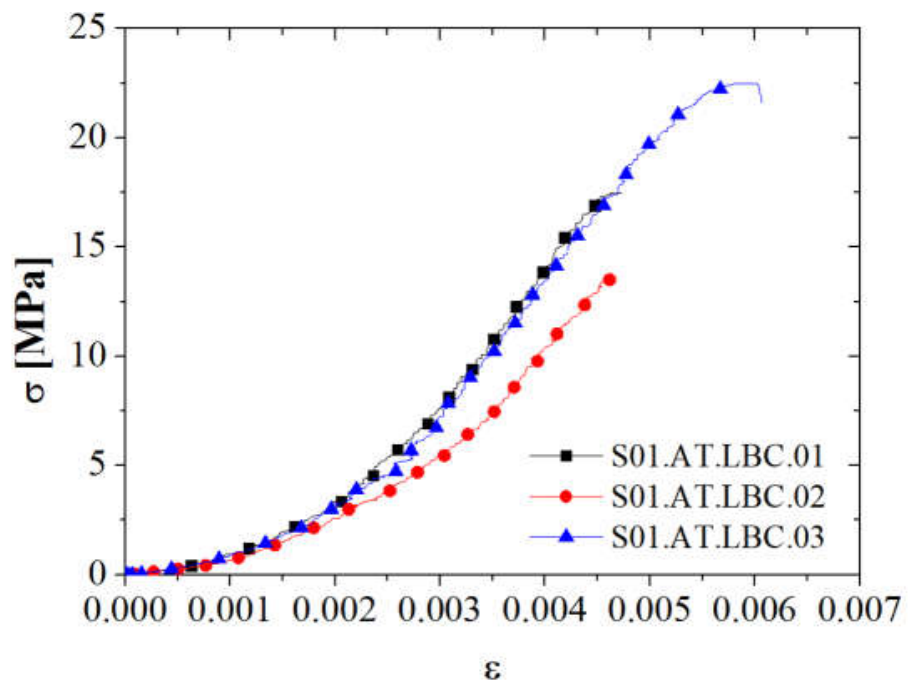

Figure 9 - Test series S01.AT.LBC - Stress-strain curves

During stage $i i$, a linear behaviour was observed in the stress-strain curves, however the Young's modulus of the wall $\left(E_{\text {wall }}=6.2 \mathrm{GPa}\right)$ was significant smaller than the Young's modulus of the brick $\left(E_{\text {brick }}=28.8 \mathrm{GPa}\right)$, indicating a non-homogeneous stress distribution in the wall, mostly caused by the bricks' shape imperfections. It is worth mentioning that the modulus of elasticity was obtained by ultrasonic pulse velocity tests, this method usually gives higher values than the ones obtained by a classical compression tests. 
Nevertheless, the stresses concentrations are evidenced. Ngapeya et al [11] evaluated the influence of the bricks' shape imperfections on the loadbearing capacity of dry-stacked masonry. The authors observed that the non-homogeneous stress distributions along the wall leads to a reduction of its structural capacity. The non-homogeneous stress distribution in the wall was also evidenced by the DIC analysis. Figure 10 presents the measured in-plane displacement fields (vertical direction) for specimens S01.AT.LBC.02 and S01.AT.LBC.03, the stress level and the average strains measured by the LVDTs are also presented.

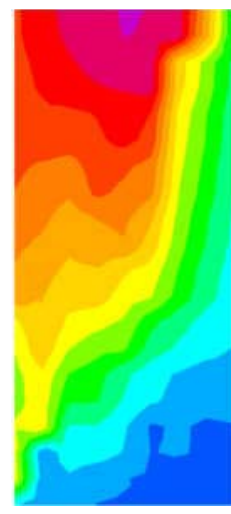

$(13.5 \mathrm{MPa})$

$\left(\varepsilon_{\text {avg }}=0.0047\right)$

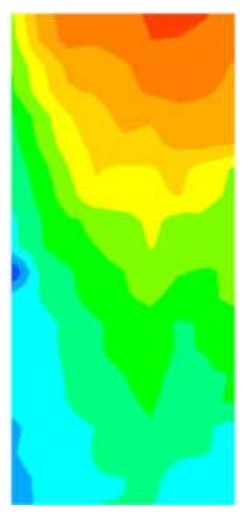

$(13.5 \mathrm{MPa})$

$\left(\varepsilon_{\text {avg }}=0.0040\right)$

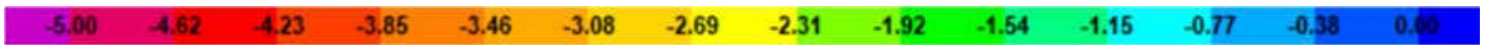

a)

b)

Figure 10 - Test series S01 - In-plane displacement fields: a) S01.AT.LBC.02; b) S01.AT. LBC.03 (in mm)

During stage iii, a slightly decrease of the wall's Young's modulus was observed, which is typical of masonry due to the development of cracks in the material. These cracks are mostly thin and distributed in the specimen, with very brittle failure. The compressive strength for specimens S01.AT. LBC.01, S01.AT. LBC.02 and S01.AT. LBC.03 was 17.5 MPa, 13.5 MPa and 22.5 MPa, respectively. Specimen S01.AT.LBC.02, presented a low compressive strength due to an uneven load distribution in the specimen, caused by a large shape imperfection, as observed in the DIC analysis (Figure 10a). The average compressive strength was $17.8 \mathrm{MPa}$ (20.0 MPa if specimen S01.AT.LBC.02 is disregarded). The failure sequence is presented in Figure 11. 


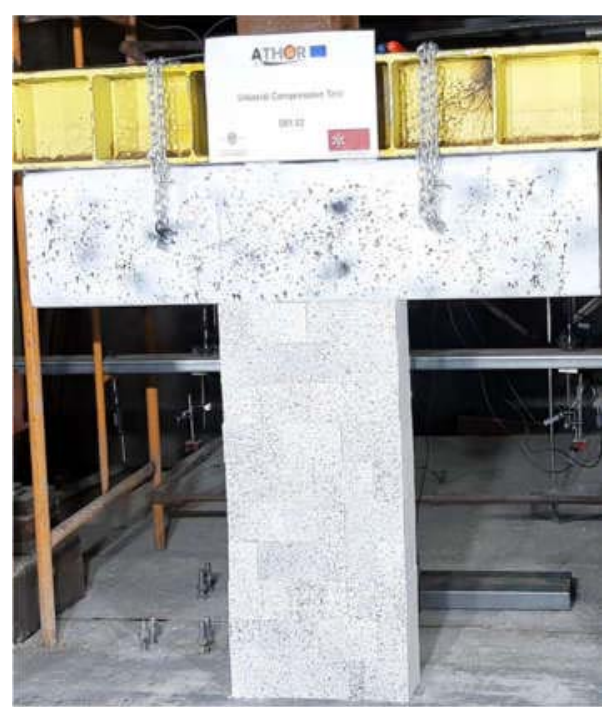

a)

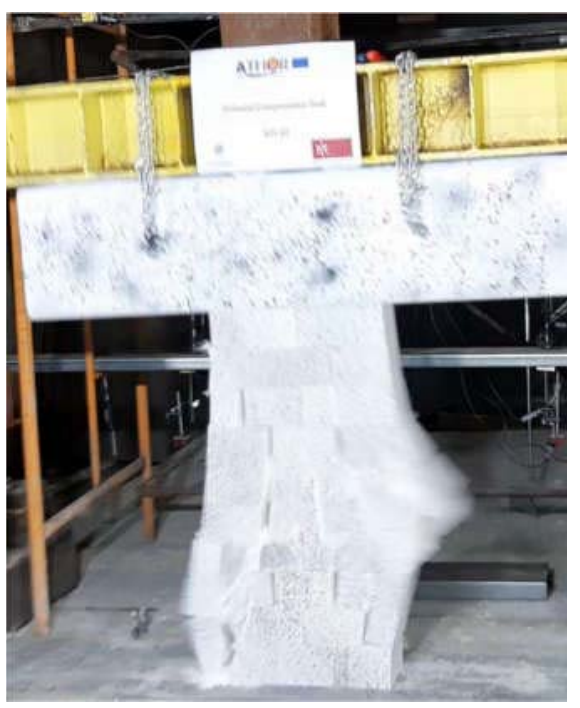

b)

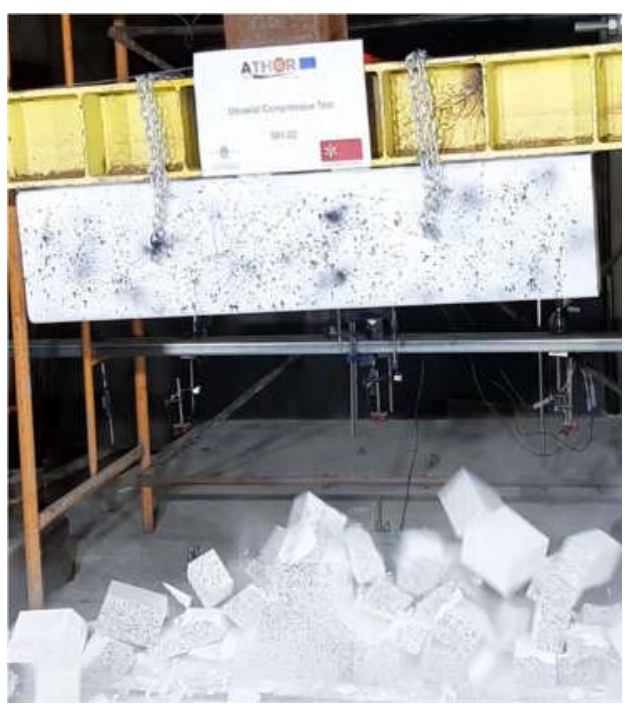

c)

Figure 11 - Test series S01 - Images of testing sequence: a) Before testing; b) Failure; c) After testing

\subsection{Test series S02.AT.CIC}

Figure 12 presents the stress-strain curves obtained experimentally for test series S02.AT.CIC. An increasing residual strain was observed after each loading cycle, as a result of the initial crushing of the non-flat surfaces in contact at the bed joints (Figure 13a). This crushing happened during the loading cycles and resulted in the increasing of the contact area between the bricks, consequently also increasing the Young's modulus of the wall. The evolution of the Young's modulus of specimen S02.AT.CIC.02, determined from the tangent curves, with the load cycles can be observed in Figure 13b. The values presented are the maximum Young's modulus measured for the respective cycle. The values measured during the loading and unloading stages are presented in blue and red, respectively. The numbers in the subscript stand for the load cycle and the letter L and U stand for loading and unloading stages, respectively. The Young's modulus of the wall (13.0 GPa in the last unloading cycle) was, again, much smaller than the one of the material (28.8 GPa). 


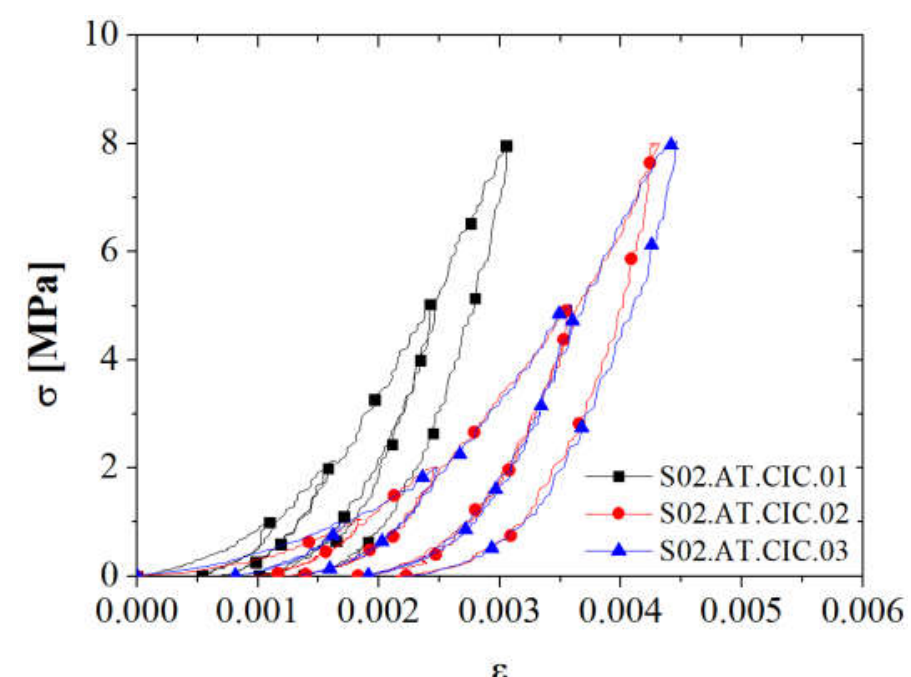

Figure 12 - Test series S02.AT.CIC - stress-strain curves

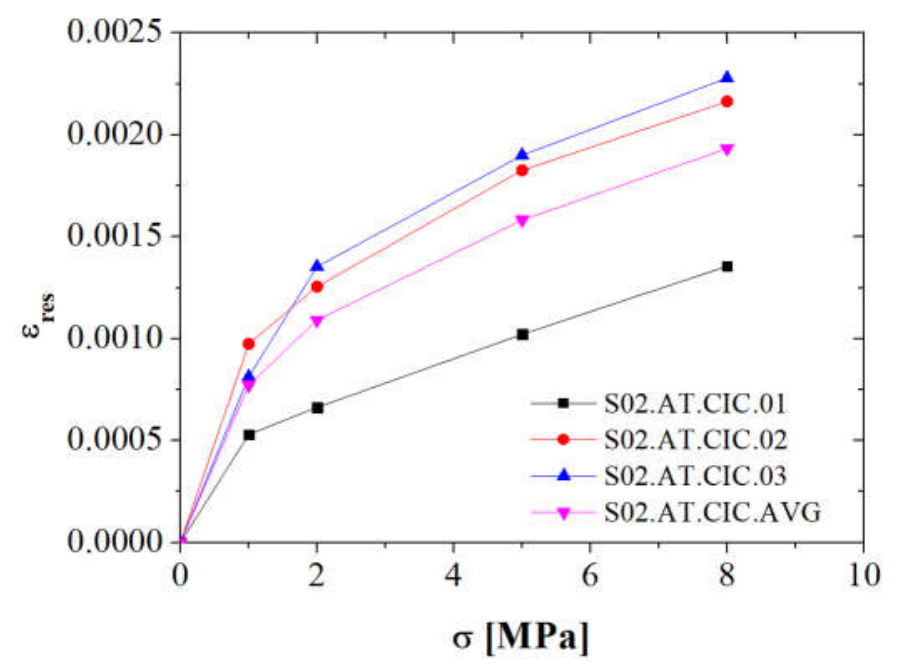

a)

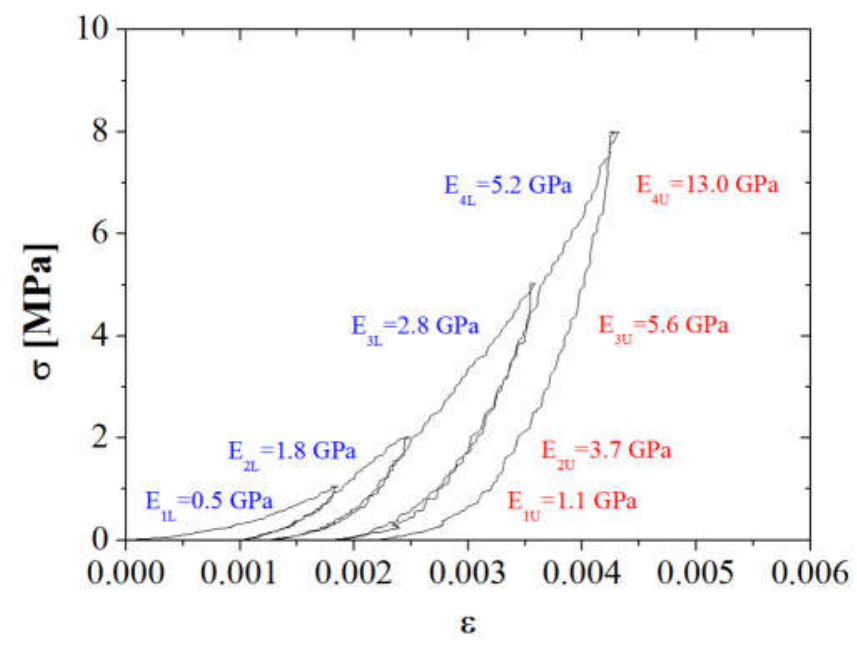

b)

Figure 13 - Test series S02.AT.CIC - Joint crushing process: a) Evolution of residual strain with load level; b) Evolution of wall's Young's modulus after joint crushing

The bricks' shape imperfections are the main contributor for the unevenness stress distribution obtained along the wall [11], as observed in Series S01.AT.LBC. Figure 14 presents the in-plane (vertical direction) displacement fields measured by DIC for specimen S02.AT.CIC.02, the stress level and the average strains measured by the LVDTs are also presented.. The flow of in-plane forces can be easily identified, the regions with higher displacements indicates the presence of two pressure bulbs in the wall. It is also observed that the residual displacements are higher in the areas of the pressure bulbs. 


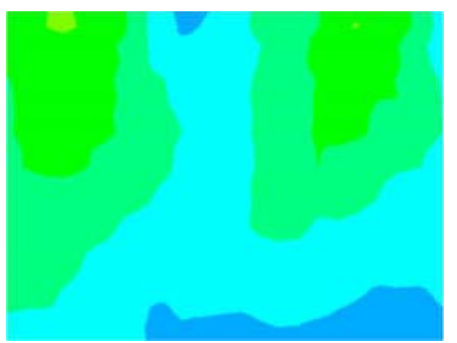

$1^{\text {st }}$ load level

Loading (1MPa)

$\left(\varepsilon_{\mathrm{avg}}=0.0019\right)$

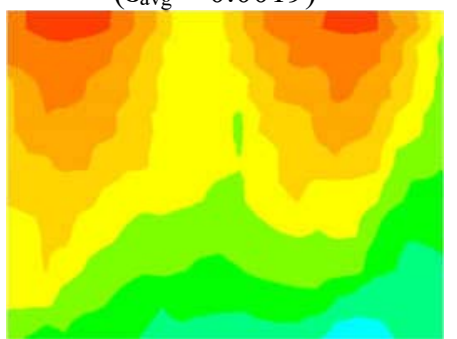

$3^{\text {rd }}$ load level

Loading (5MPa)

$\left(\varepsilon_{\mathrm{avg}}=0.0036\right)$

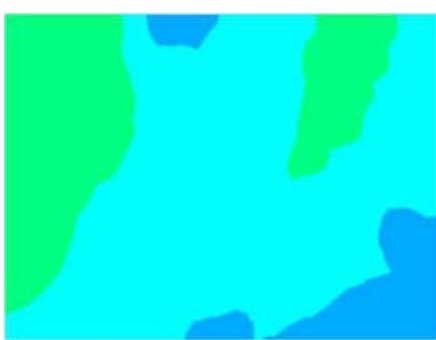

$1^{\text {st }}$ load level

Unloading (0MPa)

$\left(\varepsilon_{\mathrm{avg}}=0.0010\right)$

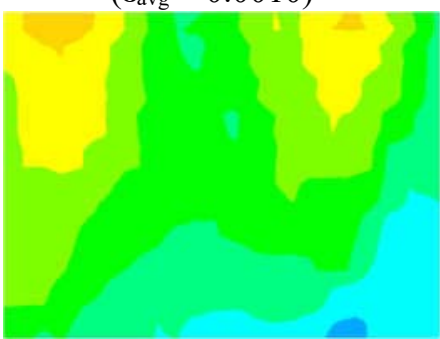

$3^{\text {rd }}$ load level

Unloading (0MPa)

$\left(\varepsilon_{\mathrm{avg}}=0.0018\right)$

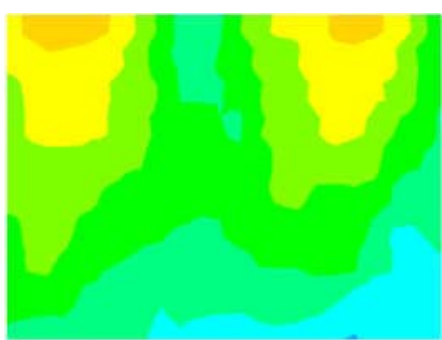

$2^{\text {nd }}$ load level

Loading (2MPa)

$\left(\varepsilon_{\mathrm{avg}}=0.0025\right)$

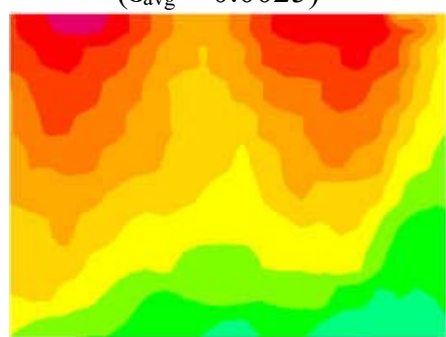

$4^{\text {th }}$ load level

Loading (8MPa)

$\left(\varepsilon_{\text {avg }}=0.0043\right)$

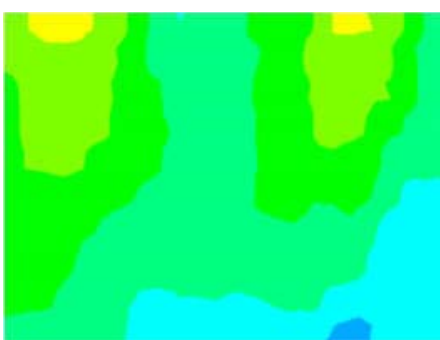

$2^{\text {nd }}$ load level

Unloading (0MPa)

$\left(\varepsilon_{\mathrm{avg}}=0.0012\right)$

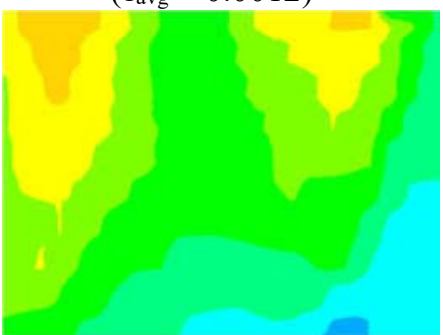

$4^{\text {th }}$ load level

Unloading (0MPa)

$\left(\varepsilon_{\text {avg }}=0.0021\right)$

Figure 14 -In plane displacement fields measured by DIC for test series S02.AT.CIC.02 [in mm]

The bricks' shape imperfections in dry-stacked masonry leads to stress concentrations in the wall [11].

Consequently, it was possible to observe cracks even for low load levels (Figure 15). The cracks were mostly located in the middle of the bricks and caused by the non-uniform loading and support conditions of the blocks.
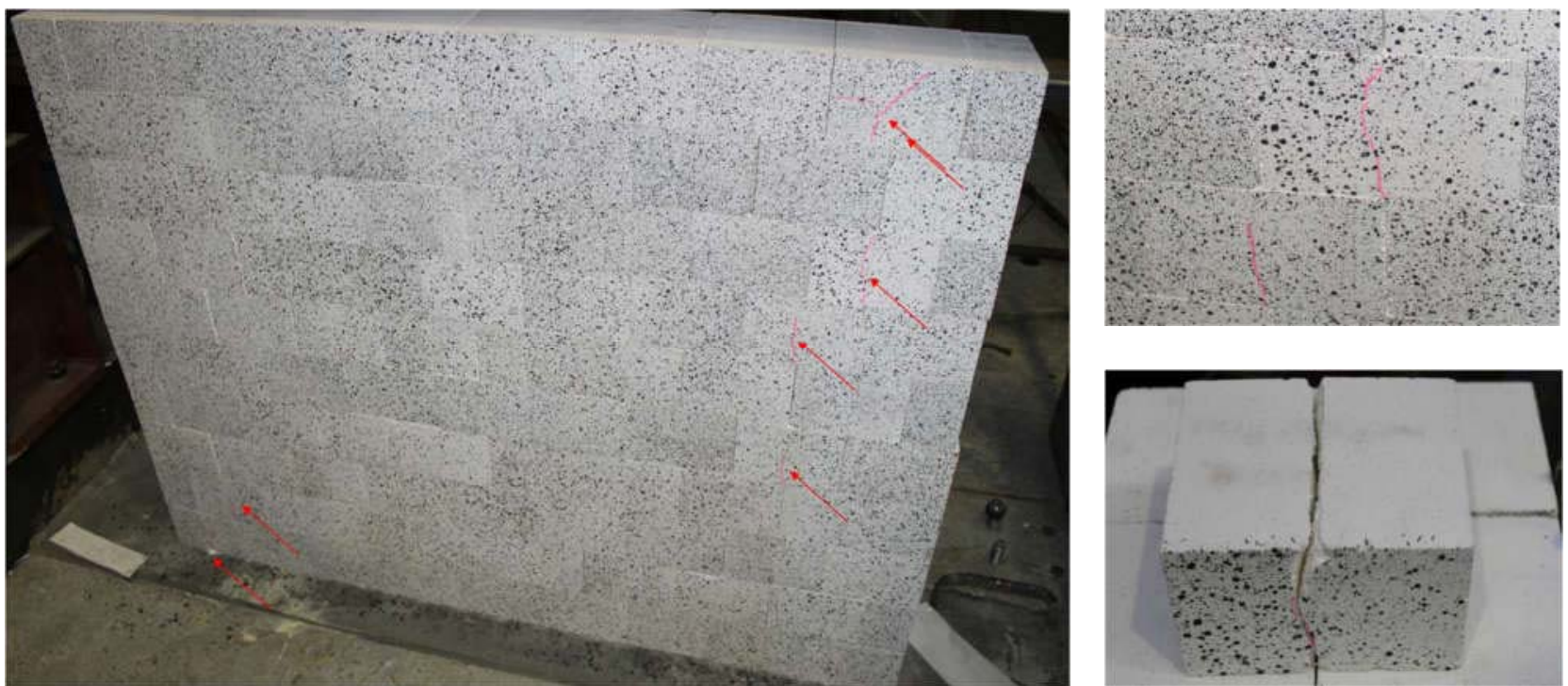

Figure 15 - Test series S02.AT.CIC: Cracks patterns observed by the end of the test 


\subsection{Test series S03.HT.LL8}

The temperatures measured by the thermocouples embedded in the bricks are presented in Figure 16. The curves presented in red, ISO 834-1 and Furnace, are the standard fire curve and the temperature measured in the furnace, respectively. The curves presented in orange and magenta are the measured temperatures in the hot face (HF) and in the cold face (CF), respectively. The maximum (Max), minimum (Min) and average (Avg) measured values in each face were presented. The purple dashed line stands for the beginning of the heating process.

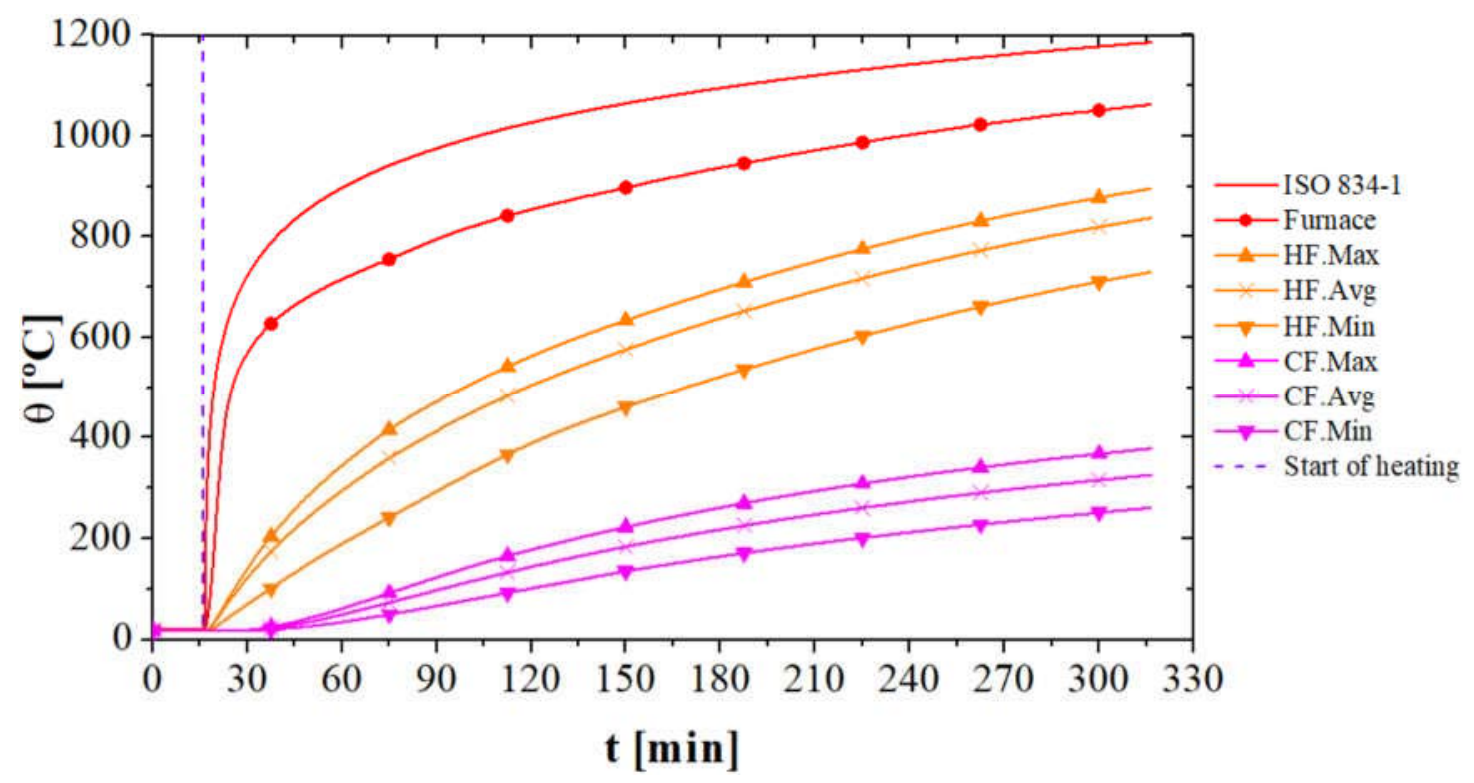

Figure 16 - Test series S03.HT.LL8: Temperature evolution

Due to the high thermal capacitance of the specimen, the furnace was not able to follow the programmed curve. The temperatures in the hot face started to increase rapidly when the thermal load is applied. Due to the relatively low thermal conductivity of refractory materials, the temperatures on the cold face took some time to start increasing. The temperatures in the first course of the bricks (bottom of the wall) were lower than the average temperatures of the wall. This was caused in part by the furnace's internal arrangement of resistances, making this area less exposed to radiation, due to heat losses through the reaction slab, and due to the air convective currents inside the furnace. However, a relatively homogeneous temperature distribution was found in the wall within a range of $\pm 15 \%$. The average thermal gradient through the thickness of the wall 
reached $512{ }^{\circ} \mathrm{C}$ by the end of the test. The difference between the average and the maximum temperatures measured were also slightly influenced by the depth at which the thermocouples were embedded.

The average of the measured in-plane strains is presented in Figure 17. At the beginning of the test, from 0 to 20 minutes, the pre-compression stress of $8 \mathrm{MPa}$ was applied and negative displacements were observed, as a result of the joint closure and brick's deformation. The maximum displacements after load application were $3.12 \mathrm{~mm}(\varepsilon=-0.0031),-3.76 \mathrm{~mm}(\varepsilon=-0.0038)$ and $-3.49 \mathrm{~mm}(\varepsilon=-0.0035)$ for specimens S03.HT.LL8.01, S03.HT.LL8.02 and S03.HT.LL8.03, respectively.

At 20 minutes after the beginning of the test, the furnace was turned on and the temperatures at the hot face started to increase. After 45 to 60 minutes of the beginning of the test, the effects of the thermal elongation started to rise and the wall presented a positive strain rate. The thermal elongation surpassed the displacements caused by the mechanical loading after $244 \mathrm{~min}, 249 \mathrm{~min}$ and $252 \mathrm{~min}$ of the beginning of the test, for specimens S03.HT.LL8.01, S03.HT.LL8.02 and S03.HT.LL8.03, respectively. Test S03.HT.LL8.01 was stopped after 265 minutes, with a positive displacement of $0.24 \mathrm{~mm}(\varepsilon=0.0002)$. Tests S03.HT.LL8.02 and S03.HT.LL8.03 were stopped after 300 minutes, with maximum displacements of $0.61 \mathrm{~mm}(\varepsilon=0.0006)$ and $0.80 \mathrm{~mm}(\varepsilon=0.0008)$, respectively.

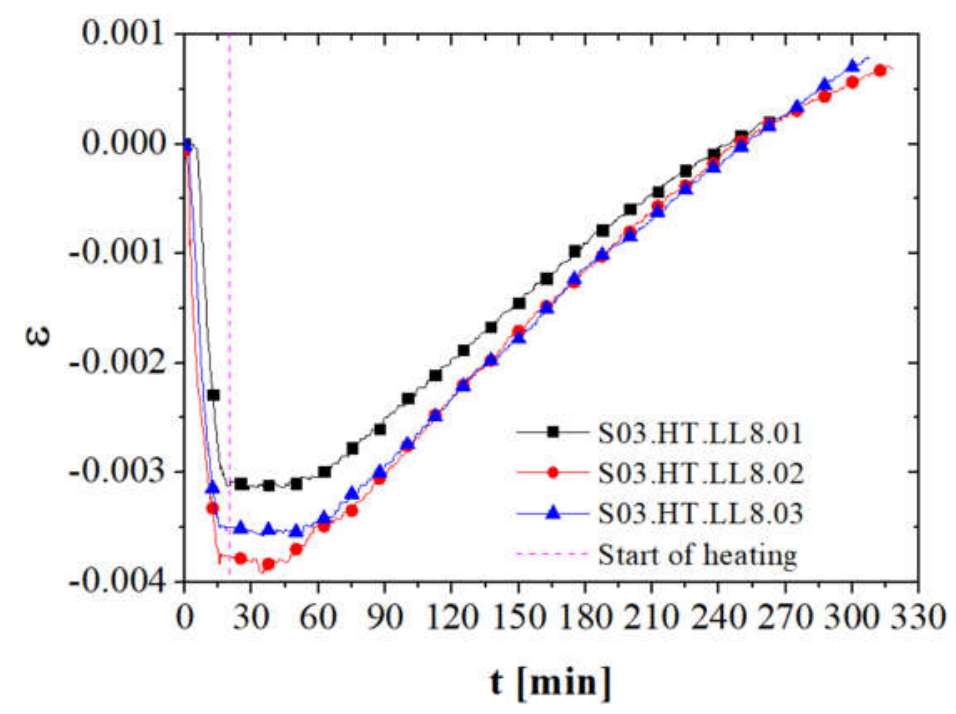

Figure 17 - Test series S03.HT.LL8 - In-plane strains

In spite of the relatively low load level in the wall, some cracks were observed in the specimen upon completion of the test. Figure 18a shows the cracks observed in the interface between the load application 
beam and the wall's top surface. These cracks were caused by a high stress state formed in this region, due to the temperature gradient in the wall. Figure $18 \mathrm{~b}$ shows vertical cracks observed in the middle of the bricks (indicated by the red arrows), caused by the unevenness stress distribution, as discussed in Series S02.AT.CIC. The cracks of the bricks, resulted in rigid body motion on a few bricks, leading to head joint opening (indicated by the green arrows).

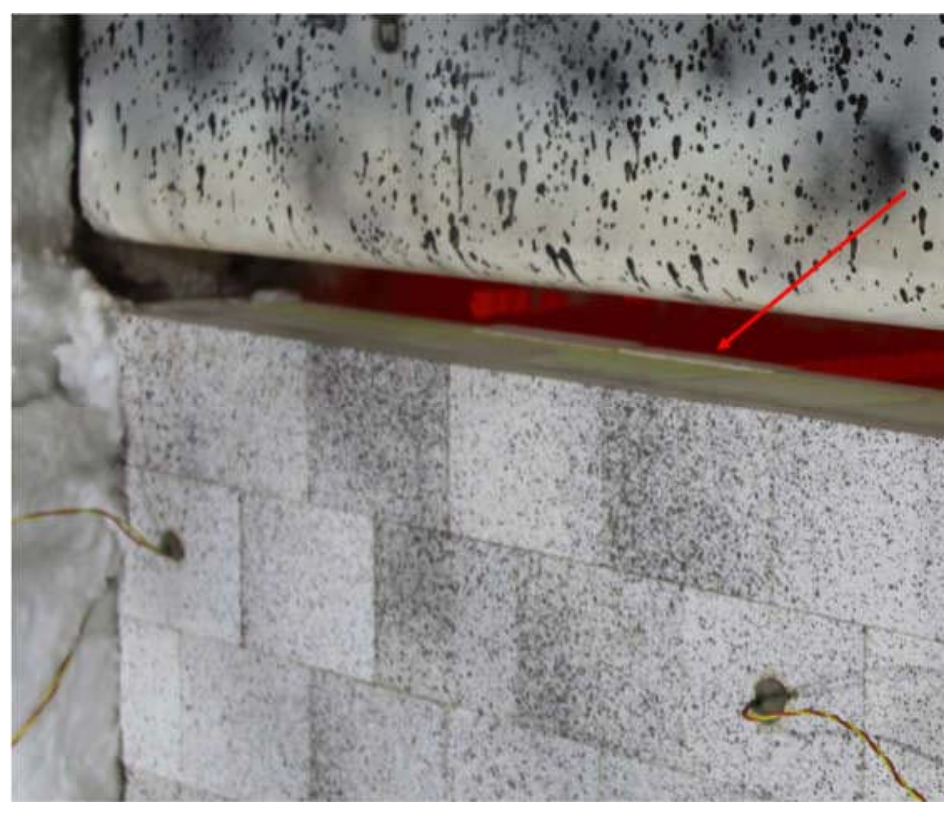

a)

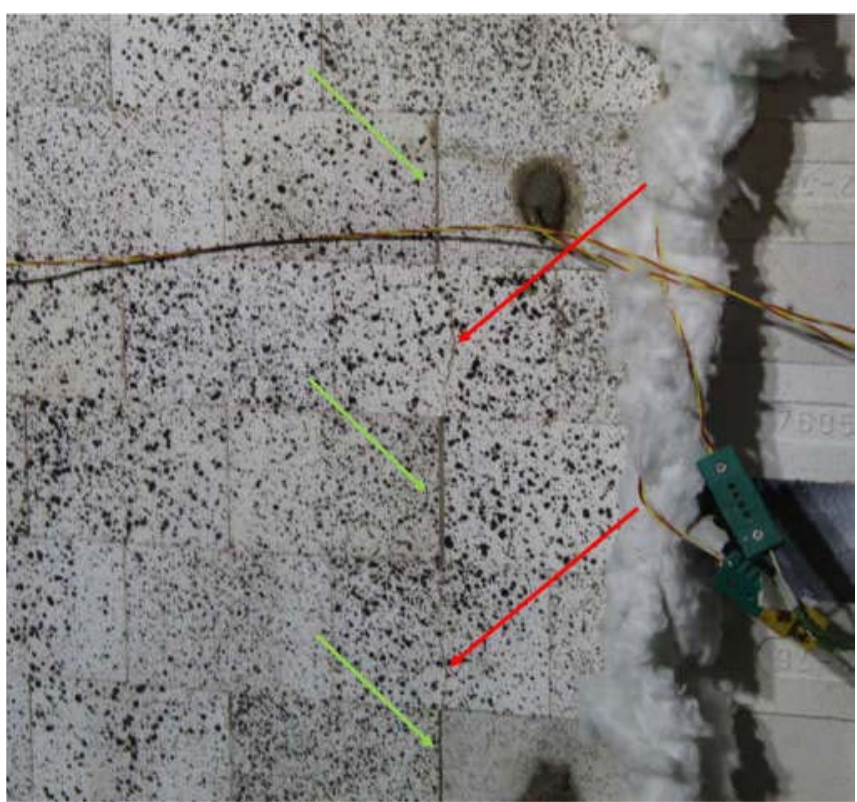

b)

Figure 18 - Test series S03 - Damage in the wall upon completion of the test: a) Cracks in the interface between load application beam and wall (S03.HT.LL8.01), b) Vertical cracks in bricks and joints openings (S03. HT.LL8.03)

\subsection{Test series S04.HT.RTE}

The temperature fields for this test series were similar to the ones found for test series S03.HT.LL8 (Figure 16). The measured vertical strains are presented in Figure 19a. At the beginning of the test, from 0 to 20 minutes, the mechanical load of $5 \mathrm{MPa}$ was applied and a negative displacement was observed, as a result of the joint closure and brick's strain. The maximum displacements after load application were $-2.53 \mathrm{~mm}(\varepsilon=-$

0.0025), $-3.22 \mathrm{~mm}(\varepsilon=-0.0032)$ and $-4.15 \mathrm{~mm}(\varepsilon=-0.0042)$ for test specimens S04.HT.RTE.01, S04.HT.RTE.02 and S04.HT.RTE.03, respectively.

At 20 minutes after the beginning of the test, the furnace was turned on and the heating started, consequently the temperature increased and the effects of thermal elongation led to a positive strain rate. The thermal 
elongation surpassed the displacements caused by mechanical load after $173 \mathrm{~min}, 206 \mathrm{~min}$ and 261, for the test specimens S04.HT.RTE.01, S04.HT.RTE.02 and S04.HT.RTE.03, respectively. All tests were stopped after 320 minutes. At this moment, the maximum displacements observed were $2.31 \mathrm{~mm}(\varepsilon=0.0023), 1.74 \mathrm{~mm}$ $(\varepsilon=0.0017)$ and $0.75 \mathrm{~mm}(\varepsilon=0.0008)$ for test specimens S04.HT.RTE.01, S04.HT.RTE.02 and S04.HT.RTE.03, respectively.

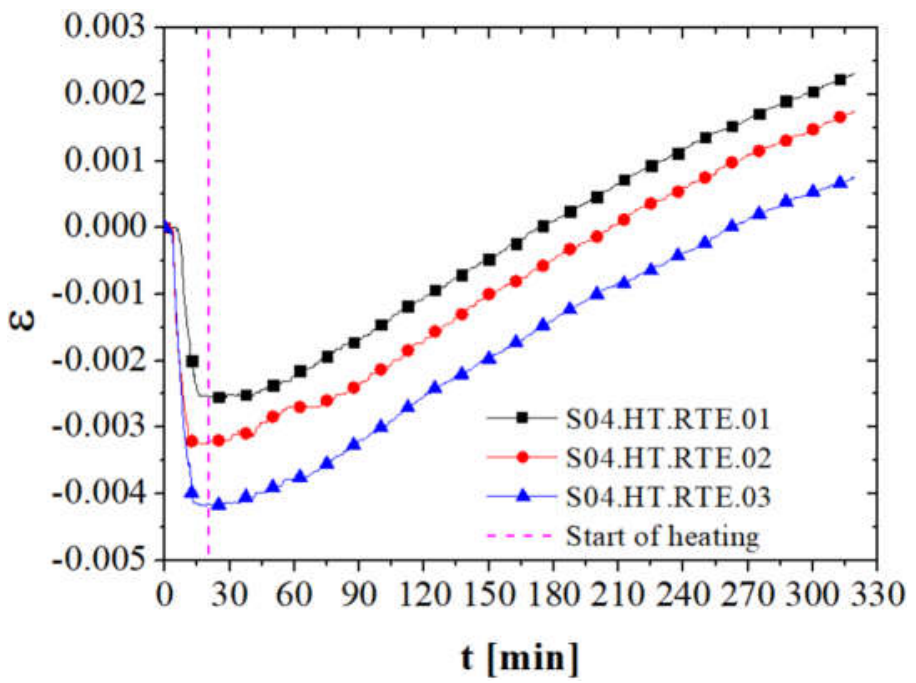

a)

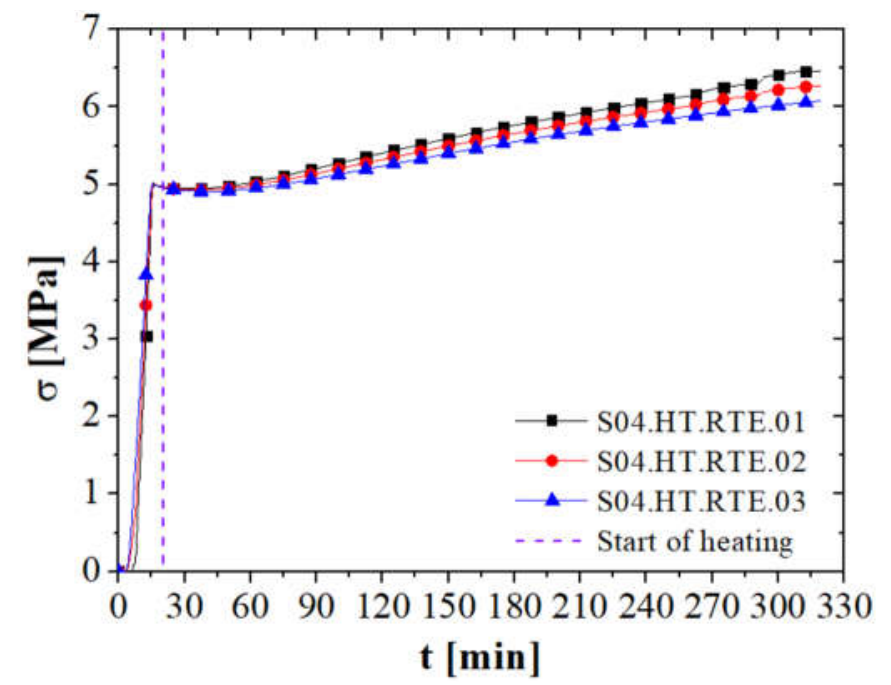

b)

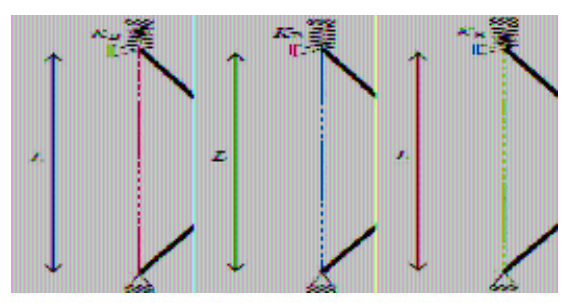

c)

Figure 19 - Test series S04.HT.RTE a) In-plane strains, b) Stresses; c) Structural schematics

During the heating stage of series S04.HT.RTE the hydraulic jack was set to be blocked at its current position, in fact the LVDT used to feed the servo-controller unit of the jack did not presented measurements during the heating stage. However, the reaction frame (composed by two HEB500 columns and two HEB600 beams) worked as a spring with axial stiffness $\mathrm{K}_{\mathrm{B}}$ (see Fig.19 c). The increasing of the vertical load in the wall caused 
by the restrained thermal elongation led to displacements in the reaction frame and consequently to strains in the wall.

Figure $19 \mathrm{~b}$ presents the evolution of the stresses developed in the sample. From 0 to 20 minutes, a pre-load of $5 \mathrm{MPa}$ was applied. Then, the position of the hydraulic jack was blocked and the thermal load was applied. As expected, the thermal elongation led to an increasing compressive force in the wall. By the end of the test, the measured stresses for test series S04.HT.RTE.01, S04.HT.RTE.02 and S04.HT.RTE.03 were 6.47 MPa, 6.22 $\mathrm{MPa}$ and $6.08 \mathrm{MPa}$, respectively.

Despite the relatively low load level in the wall, again some cracks were observed, as for example the ones between the load application beam and the wall's top surface in specimen S03.HT.LL8. Figure 20 presents vertical cracks observed in the middle of the bricks (indicated by the red arrows), caused by an unevenness stress distribution, as discussed in test series S02.AT.CIC and S03.HT.LL8. Rigid body motions caused by the cracks in the bricks were also observed, leading to head joint opening (indicated by the green arrows).

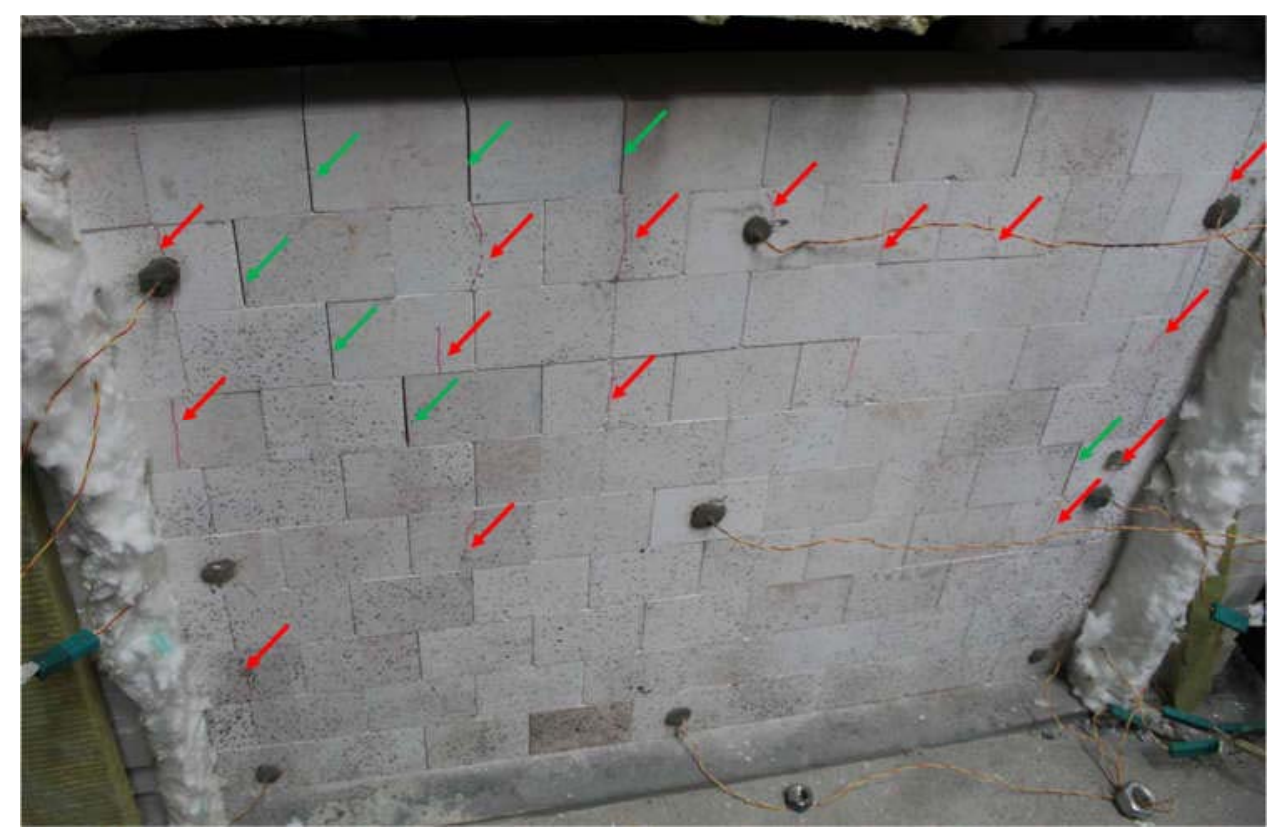

Figure 20 - Test series S04.HT.RTE - Failures in the wall: Vertical cracks in bricks and joints openings (S04.HT.RTE.02)

\subsection{Test series S05.HT.LL10}

The measured temperatures are presented in Figure 21a and Figure 21b for specimens S05.HT.LL10.01 and S05.HT.LL10.02, respectively. The temperatures in specimen S05.HT.LL10.02 were slightly higher than the 
other specimen, due to the fact that insulation was placed in the cold face of the wall. The objective was to heat the specimen as much as possible.

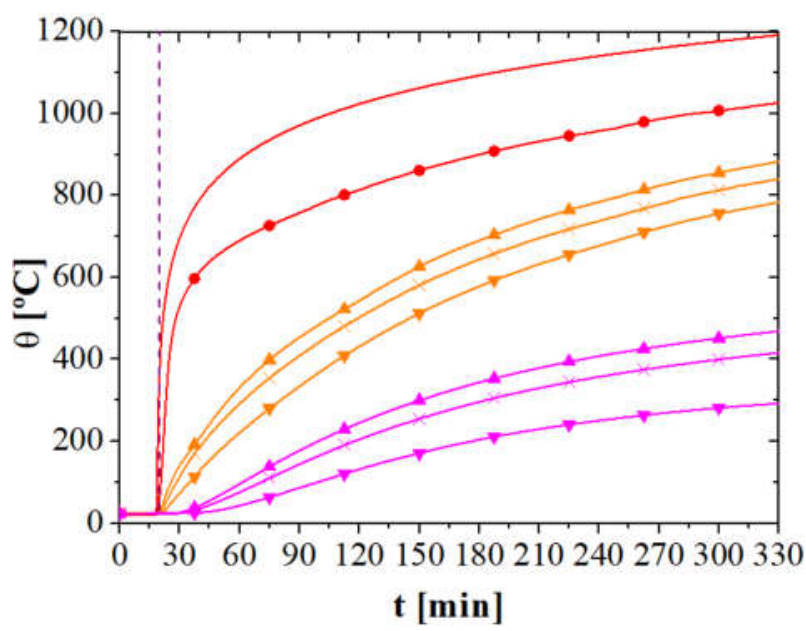

a)

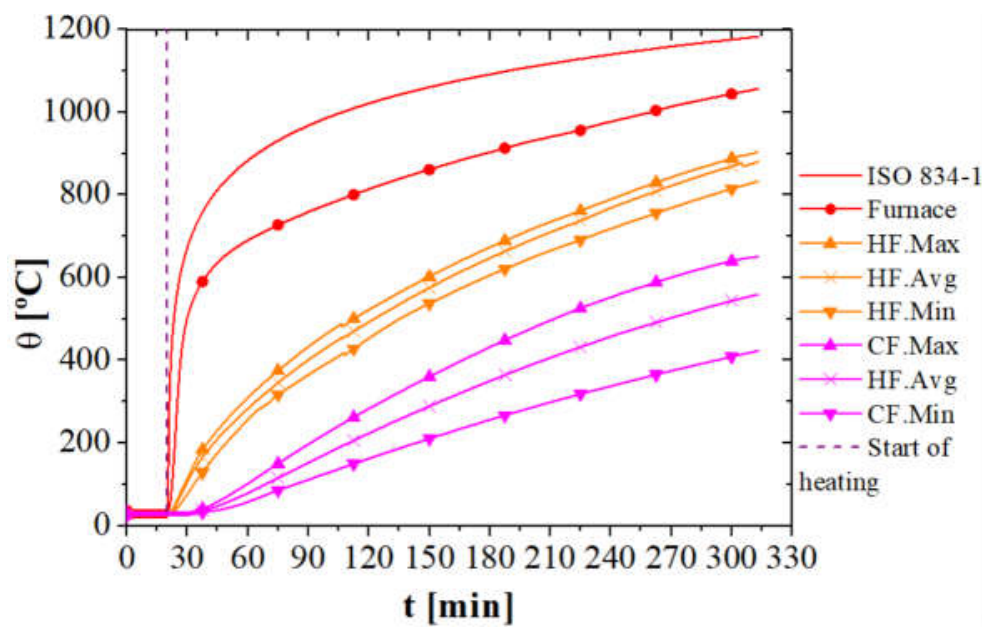

b)

Figure 21 - Test series S05.HT.LL10 - Temperatures a) S05.HT.LL10.01; b) S05.HT.LL10.02

The average of the measured in-plane strains is presented in Figure 22. At the beginning of the test, from 0 to 20 minutes, the load was applied and a negative displacement was again observed. The displacements after load application were $-5.25 \mathrm{~mm}(\varepsilon=-0.0053)$ and $-4.86(\varepsilon=-0.0049) \mathrm{mm}$ for specimens S05.HT.LL10.01 and S05.HT.LL10.02, respectively.

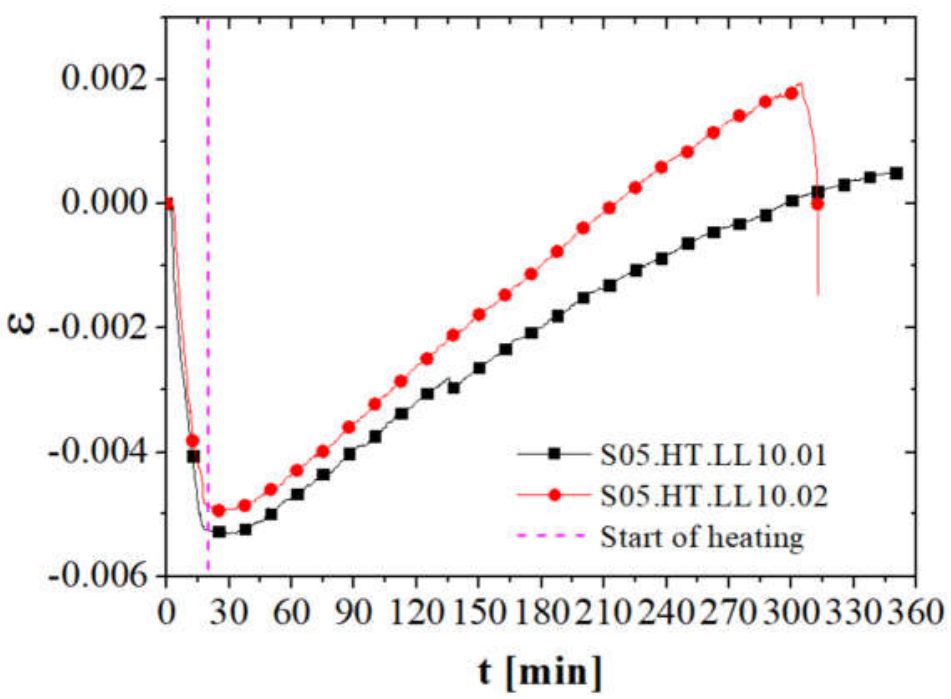

Figure 22 - Test series S05.HT.LL10: Vertical strains 
When the furnace was turned on (at 20 minutes) the temperatures at the hot face started to increase, consequently the thermal elongation started and the wall presented a positive strain rate. The thermal elongation surpassed the displacements caused by the mechanical load after $296 \mathrm{~min}$ and 214 min for specimens S05.HT.LL10.01 and S05.HT.LL10.02, respectively.

The test for specimen S05.HT.LL10.01 was stopped after 360 minutes. At this moment a positive displacement of $0.49 \mathrm{~mm}(\varepsilon=0.0005)$ was registered. The failure of this specimen was not observed in the test. Nevertheless, some cracks and crushing points were observed in the specimen, as shown in Figure 23a. The temperatures in specimen S05.HT.LL10.02 increased slightly faster in comparison with the other specimen due to the thermal insulation installed in front of the wall. As shown in Figure 22, the strain rate of S05.HT.LL10.02 was higher as the thermal elongation is more significant. The thermal gradient in the wall led to significant thermal bowing, defined as an out-of-plane displacement of the specimen. The thermal bowing caused an eccentricity in the vertical load and led to sudden failure of the wall, as seen in Figure 23b.

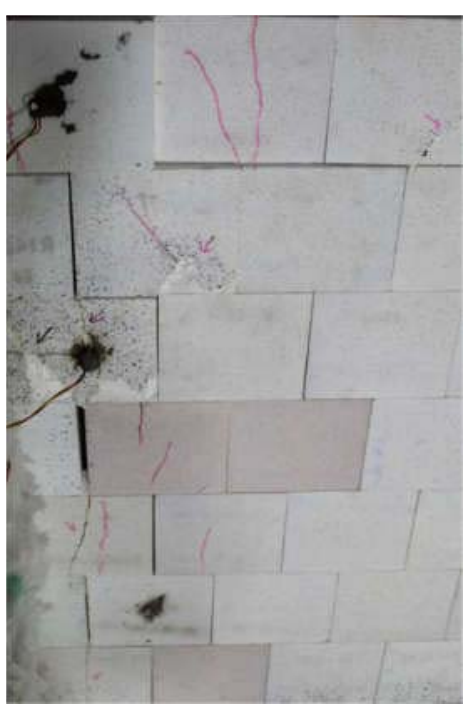

a)

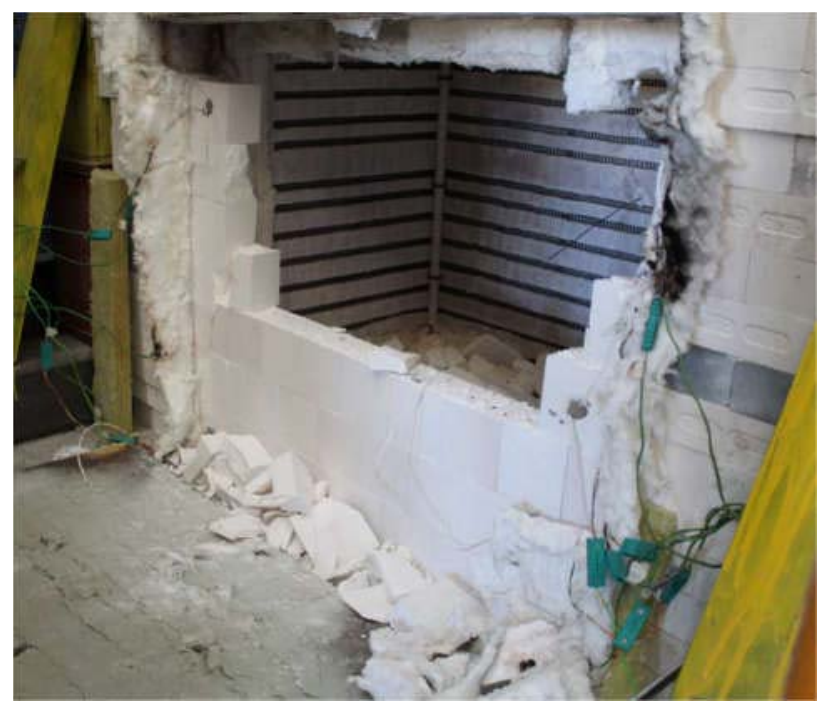

b)

Figure 23 - Test series S05 - Damage to the wall: a) Vertical cracks in bricks and joint openings in specimen S05.HT.LL10.01;

b) Complete failure of specimen S05.HT.LL10.02 


\section{Numerical analysis}

The thermomechanical analysis of masonry structures encompasses different possible techniques. In the micro-modelling approach, the units and mortar are modelled as continuum elements and the interfaces between bricks and mortar (or between bricks and bricks) are represented by discontinuum elements. In the macro-modelling approach, the units and the interfaces are represented by continuum elements [40, 41]. Homogenization techniques may also be used to simulate masonry [30, 42]. The micro-modelling approach leads to more accurate results, but its main drawback is the large computational resources required to run the analysis $[11,42]$. Nevertheless, this approach provides detailed results on the behaviour of the bricks and joints and, therefore, was adopted in this study. The numerical analyses were performed using the finite element software Abaqus [43]. The geometry of the model was based on the description provided in section 2 (Figure 3) and Figure 24 presents the developed model for the different testing series.

The masonry walls were discretized using 8-node solid elements. The final mesh was generated automatically by Abaqus software and was rather refined (280 elements per brick and 140 elements per half brick). The influence of the finite element size on the thermomechanical behaviour of the masonry walls was evaluated, $30 \mathrm{~mm}, 20 \mathrm{~mm}$ and $10 \mathrm{~mm}$ elements were used in the mesh study. It was found that the $20 \mathrm{~mm} \times 20 \mathrm{~mm} \times 20 \mathrm{~mm}$ elements led to adequate simulation results. For the heat transfer analysis, the 8-node linear heat transfer elements (DC3D8) were used. For the mechanical analysis, C3D8R elements were used, which are threedimensional continuum hexahedral brick elements with reduced integration (R), hourglass control and linear interpolation, with the usual three degrees of freedom per node (translations in directions $\mathrm{X}, \mathrm{Y}$ and Z). The use of elements with reduced integration are justified aiming to reduce the computation time, a fine mesh was used to overcome the loss of accuracy. The use of C3D8R elements have being successfully used before to simulate masonry structures in fire situations $[15,41]$. 


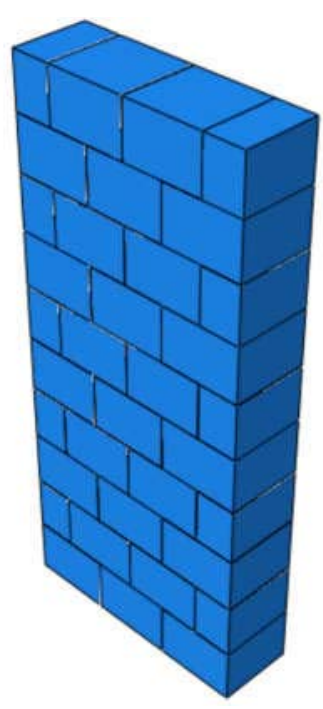

a)

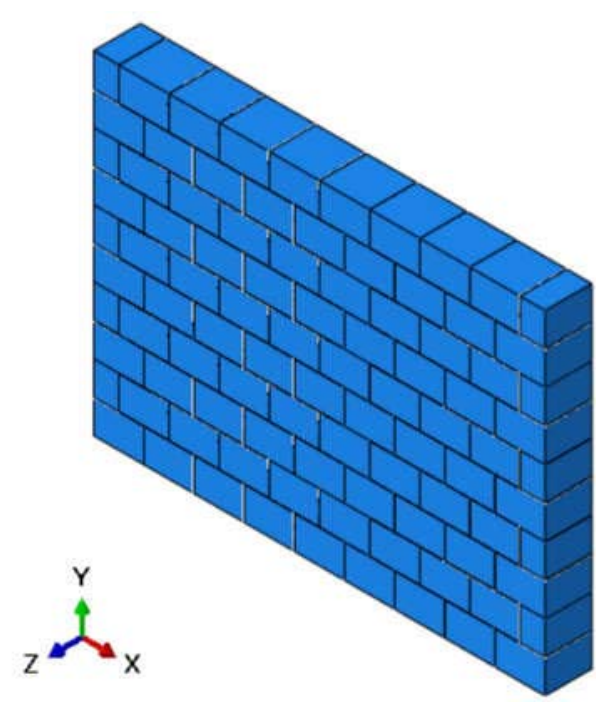

b)

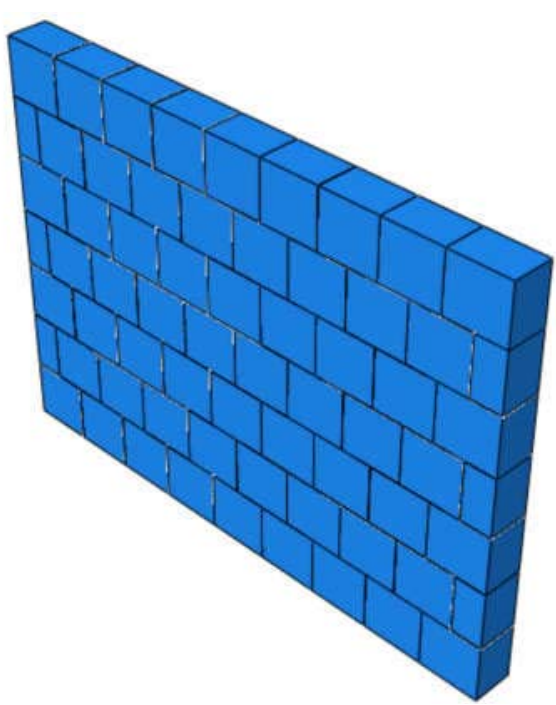

c)

Figure 24 - Numerical models for the different specimens: a) Series S01; b) Series S02, S03 and S04; c) Series S05

\subsection{Analysis procedure}

The developed finite element model comprised two analyses that were performed consecutively for each variation increment of external conditions: $i$ ) first, heat transfer analysis, and ii) second, mechanical analysis. The heat transfer analysis aims to determine the temperature fields in the wall throughout the test. The results of this analysis are used as input on the mechanical analysis. The mechanical analysis aims to simulate the structural behaviour of the dry-stacked masonry. For the tests performed at ambient temperature (S01.AT.LBC and S02.AT.CIC) only the mechanical analysis was performed.

In the heat transfer analysis, the model was fed with the thermal properties (taken as temperature-dependent) and density of the alumina spinel brick. The initial temperature of the system and the gas temperature of the furnace throughout the test were inputted in the analysis. The analysis account all of the three modes of heat transfer: convection, conduction and radiation. The interfaces between the bricks were considered to have the same thermal conductivity of the material. At the exposed and non-exposed face, the radiation was represented as a surface radiation and the convection was represented as a surface film condition. Due to the thermal insulation material used in the experimental system, adiabatic surfaces were considered between the wall and the reaction slab, the lateral masonry columns and the loading beam. Consequently, all heat losses took place on the non-exposed face. The convection coefficient was taken as $25 \mathrm{~W} / \mathrm{m}^{20} \mathrm{C}$ in the exposed face [44] and 
taken as $10 \mathrm{~W} / \mathrm{m}^{20} \mathrm{C}$ in the cold face. The resultant emissivity was taken as 0.18 . The exposed wall's surface was assumed to be, in each instant, at a constant temperature. This was confirmed by thermocouples installed in the tested specimens. Therefore, the temperature was considered to vary only through the thickness of the wall.

In the mechanical analysis, the model was fed with the bricks Young's modulus, thermal expansion coefficient, density, compressive strength and tensile strength, with the strengths taken as temperature-

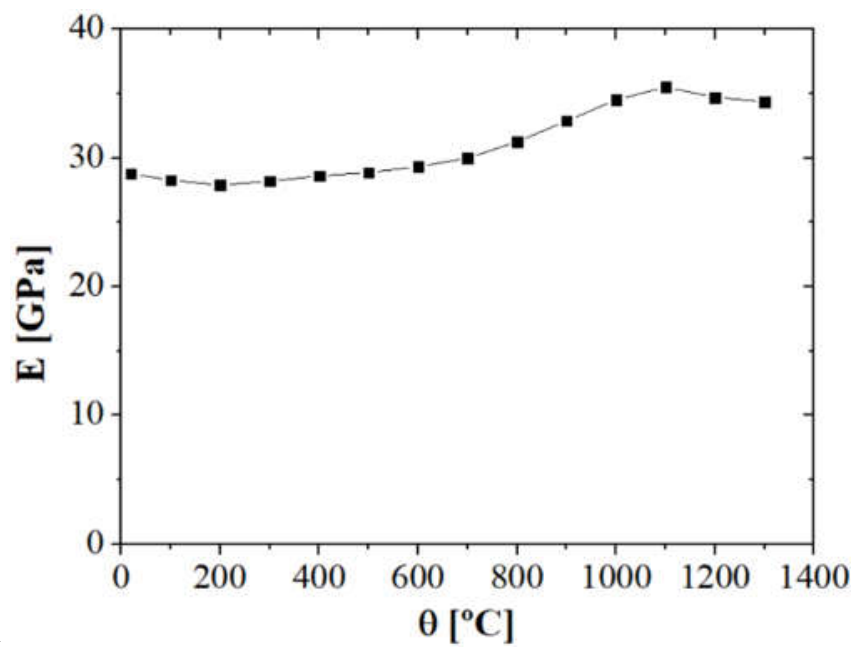

dependent as shown in Figure 1 and $\theta\left[{ }^{\circ} \mathrm{C}\right]$

Figure 2. The temperature fields generated in the heat transfer analysis were inputted in the mechanical analysis, therefore, the software uses the temperatures in each element to calculate the thermal strains and the variations in the mechanical properties. As observed in the experimental setup, the masonry support and the loading were applied on rigid elements aiming to distribute the concentrated load from the hydraulic actuator uniformly on the top and bottom surfaces of the wall. A hard contact was assumed between the masonry and the rigid elements, in other words a perfect contact condition was used, consequently, there is no overclosure or clearance between these surfaces. Suitable boundary conditions were applied at the bottom and top surfaces of the masonry, to represent the boundary conditions provided by the experimental setup.

\subsection{Material model}

The CDP (Concrete Damage Plasticity) model assumes that failure under compressive crushing and tensile cracking is defined by damage plasticity, using the concept of isotropic damage evolution for representing the inelastic behaviour of concrete like materials. The CDP model is a modification of the Drucker-Prager model $[45,46]$, however the failure surface's shape, in the deviatory plane, does not need to be a circle. The shape of the failure surfaces is defined by the parameter $K_{c}$ : the ratio of the distances between the hydrostatic axis 
and, respectively, the compression meridian and the tension meridian in the deviatory plane. $K_{c}$ was taken as 0.667. The dilation angle $(\psi)$ was taken as $20^{\circ}$, the eccentricity $(\epsilon)$ as 0.10 , the ratio of the initial equibiaxial compressive yield stress to initial uniaxial compressive stress as 1.16 and the viscosity parameter as 0.02 , as recommended in Abaqus User Manual [43]. These parameters were taken as non-temperature-dependent. The compressive and tensile strengths of the material were taken as temperature dependent (Figure 1). The material properties used in the numerical models were presented in section 2.1. It should be noted that creep was not included in these models. According to previous studies, in which the adopted material was characterized under creep for compression and tension [9,10,35,36], viscous strains are not expected at the temperature levels reached in the tests carried out in the present research.

The joints play an important role on the behaviour of dry stacked masonry and they were modelled with surface-to-surface contact properties. The joints' normal behaviour was represented by a pressure-overclosure relation. In this formulation the contact stiffness increases with the overclosure of the joint, resulting in a suitable representation of the behaviour of the dry joints. The behaviour of the dry stacked masonry depends on defects that appears during masonry building. As evidenced by Ngapeya et al [11], the increasing of the height and length of the wall reduces statistically reduces the useful section of the wall. Therefore, different relations were used to represent masonry with different dimensions. In fact, the specimen S01 had the smaller dimension and presented the bigger useful section (a higher contact area between the bricks). The general formulation of Eq. 1, provided by Thanoon et al [13], was used to model the joint behaviour. The average joint overclosure was calculated by the difference of the average displacements measured in the upper row $\left(d_{1}\right)$ and bottom row $\left(d_{2}\right)$, obtained using DIC, subtracted by the displacements caused by bricks' $\left(d_{b}\right)$ strains and divided by the number of joints (n) for each stress level, see Figure 25a. The displacements caused by bricks' strain in the studied area was calculated by $\mathrm{d}_{\mathrm{b}}=\sigma \mathrm{L} / \mathrm{E}_{\text {brick. }}$.

$$
d_{n}=\left[\left(d_{1}-d_{2}\right)-d_{b}\right] / n
$$

The average curves for each geometry is being presented in Figure 25b. 


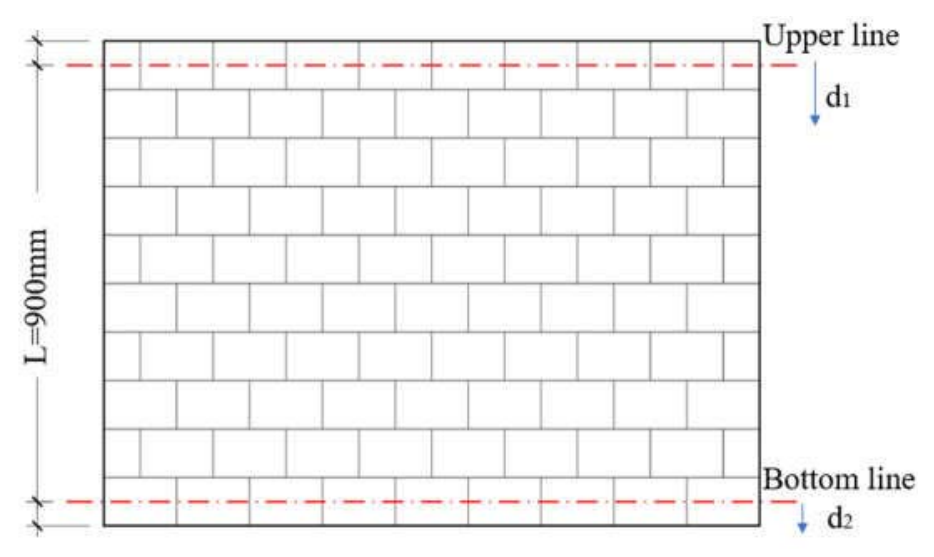

a)

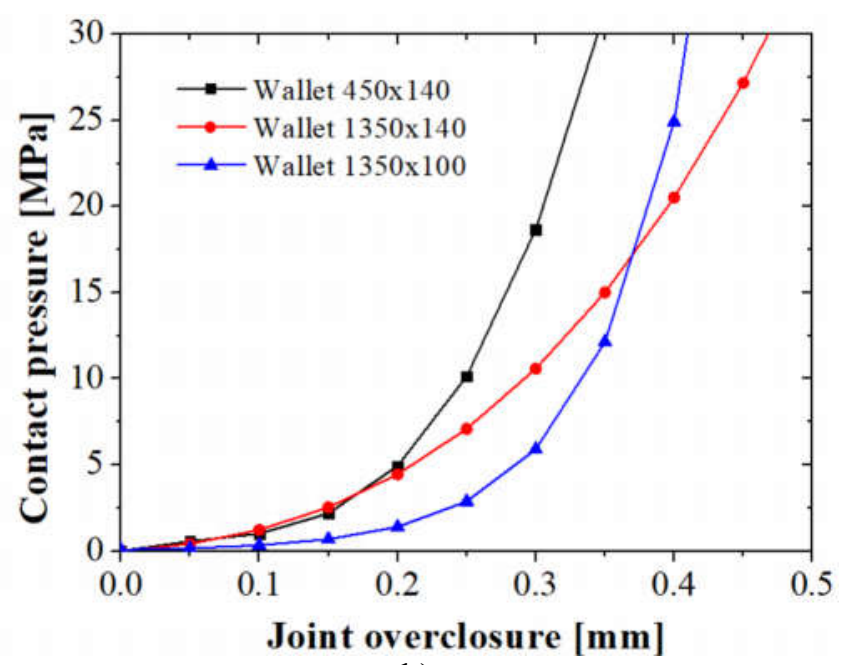

b)

Figure 25 - a) Schematics for the calculation of average joint behaviour, b)Contact pressure-overclosure relations used for different walls dimensions.

The tangential behaviour was represented by the penalty friction formulation, in which interpenetration of units is not possible and sliding is governed by the friction coefficient. The friction coefficient of the alumina bricks as a function of the temperature was obtained by Oliveira et al [33] (Table 3).

Table 3 - Friction coefficient values for dry joints and different temperatures [33]

\begin{tabular}{|c|c|}
\hline Temperature [ ${ }^{\mathbf{0}} \mathbf{C}$ ] & Friction Coefficient [-] \\
\hline 20 & 0.598 \\
\hline 300 & 0.498 \\
\hline 600 & 0.510 \\
\hline 900 & 0.530 \\
\hline
\end{tabular}

\section{Comparison between numerical and experimental results}

This section presents the comparison between the numerical and experimental results. The stress-strain curves, displacement evolution, temperature fields and failure modes obtained experimentally and numerically are compared and analysed. At the end of this section, results are discussed and analysed.

\subsection{Test series S01.AT.LBC}

Figure 26a shows the comparison of the stress-strain curves, for specimens S01.AT.LBC, obtained in the experimental and numerical tests. The curve from the FEA analysis fits closely with the experimental ones. As explained before, specimen S01.AT. LBC.02 was submitted to a significant uneven stress distribution 
(Figure 10a), therefore, its experimental curve was expected to be much lower than the other two specimens. The good agreement between the experimental and numerical results ensures the adequacy of the developed finite element model. The developed model is able to represent all of the three stages described in section 3.1: i) joint closure; ii) linear behaviour; iii) plastic behaviour and failure. Besides the stress-strain curves, also the failure mode was compared. The failure mode observed experimentally and numerically is compared in Figure $26 \mathrm{~b}$, where it is possible to observe a similar behaviour, the brick in the centre of the fifth masonry course crushed. Moreover, it was possible to identify a pattern of head joints opening in the rows bellow and above the crushing area, due to the restraint to lateral movement provided by the top and bottom supports.

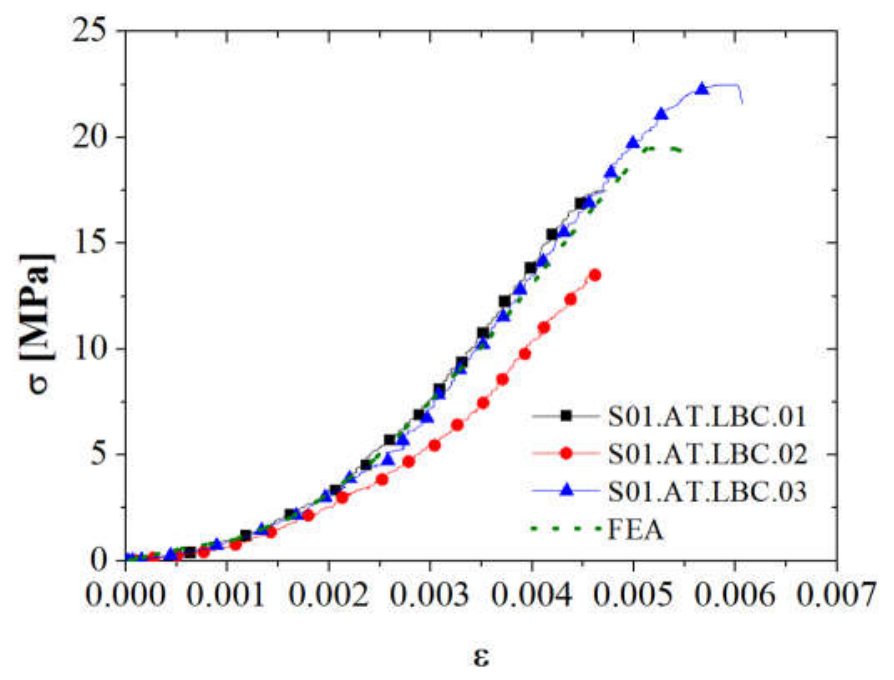

a)

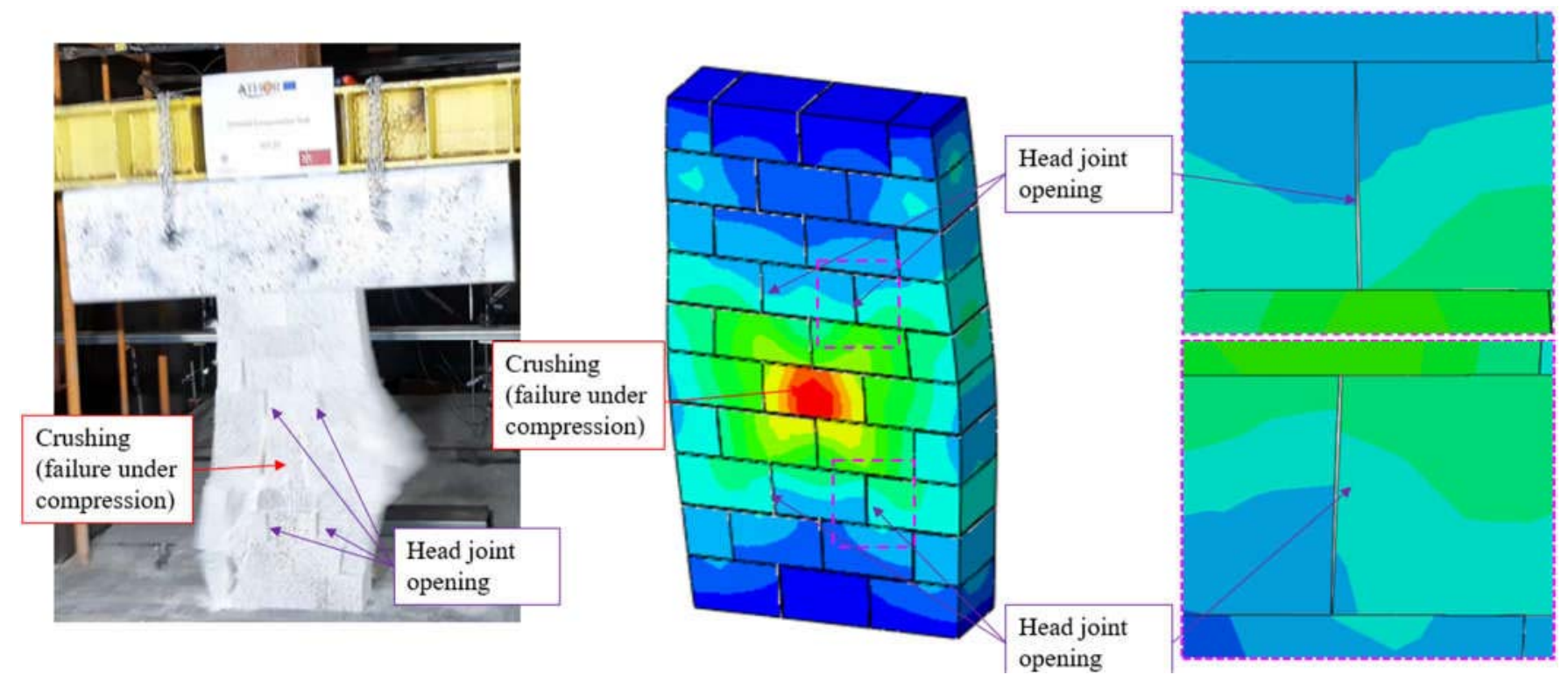

b)

Figure 26 - Validation of numerical model - test series S01.AT.LBC: a) Stress-Strain curve; b) Comparison of failure modes 


\subsection{Test series S02.AT.CIC}

Figure 27a shows the comparison of the stress-strain curves, for specimens S02.AT.CIC, obtained from the experimental tests and finite element analysis. The curve from the FEA analysis fits in the envelop defined by the loading curves of the experimental results. An acceptable agreement between the experimental and numerical results was found. Only the loading stage of the test was simulated, the developed numerical model is not able to perform the unloading stage of the test, due to limitations on the software that does not allow modifications on the pressure-overclosure relation in function of load and unload cycles. The evolution of the wall's Young's modulus in terms of the compressive stresses are presented in Figure 27b. An increase of the stiffness of the specimens is observed with the stress level.

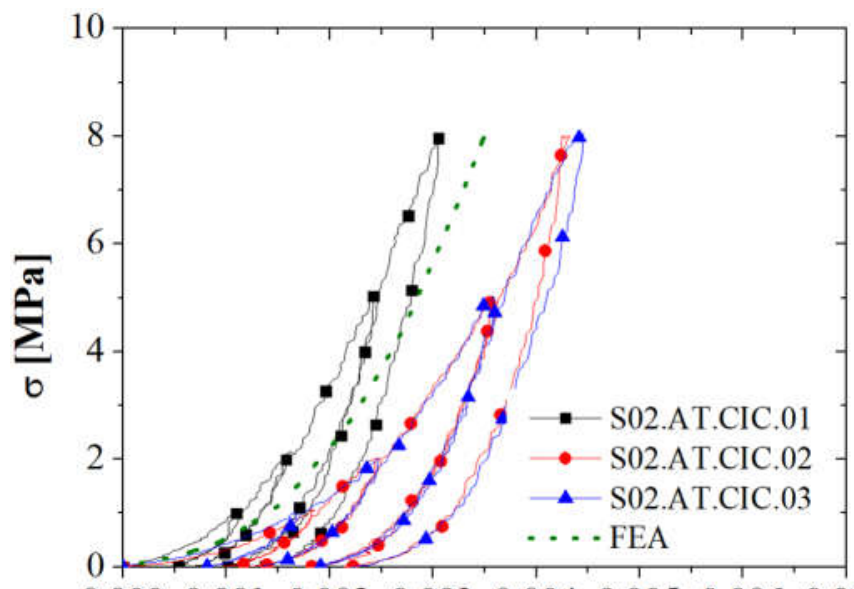

$\begin{array}{lllllllll}0.000 & 0.001 & 0.002 & 0.003 & 0.004 & 0.005 & 0.006 & 0.007\end{array}$ $\varepsilon$

a)

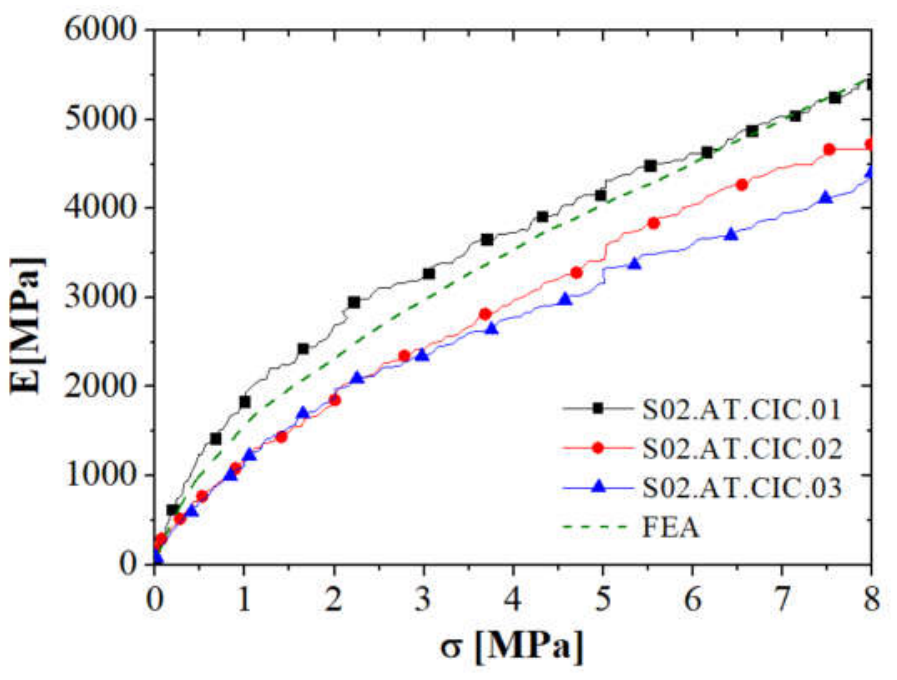

b)

Figure 27 - Validation of numerical model - test series S02.AT.CIC: a) stress-strain curves, b) evolution of wall's Young modulus with stress

\subsection{Test series S03.HT.LL8}

Figure 28a shows the comparison of temperatures obtained from the experimental and numerical tests for test series S03.HT.LL8. The curves presented in orange and magenta are the measured temperatures in the hot face $(\mathrm{HF})$ and in the cold face $(\mathrm{CF})$, respectively. The maximum (Max), minimum (Min) and average (Avg) measured values in each face were presented. The purple dashed line stands for the beginning of the heating. The temperatures calculated by the finite element analysis in the hot face (HF.FEA) and cold face (CF.FEA) 
are presented in blue and green, respectively. The temperature curves of the FEA analysis fit closely with the average of the measured temperatures. This good agreement and accuracy ensure the adequacy of the developed finite element model for the heat transfer analysis.

The model is able to represent the evolution of temperatures in the exposed and non-exposed accurately. The comparison of the in-plane strains obtained experimentally and numerically are presented in Figure $28 \mathrm{~b}$. The developed model is able to represent all stages of the test, including the effects of the thermal elongation on the masonry walls. The differences between the numerical and experimental in-plane displacements, in the interval from 20 to 45 minutes, may have been caused by rotation of the load application beam in its longitudinal axis, induced by the beginning of the thermal bowing of the wall.

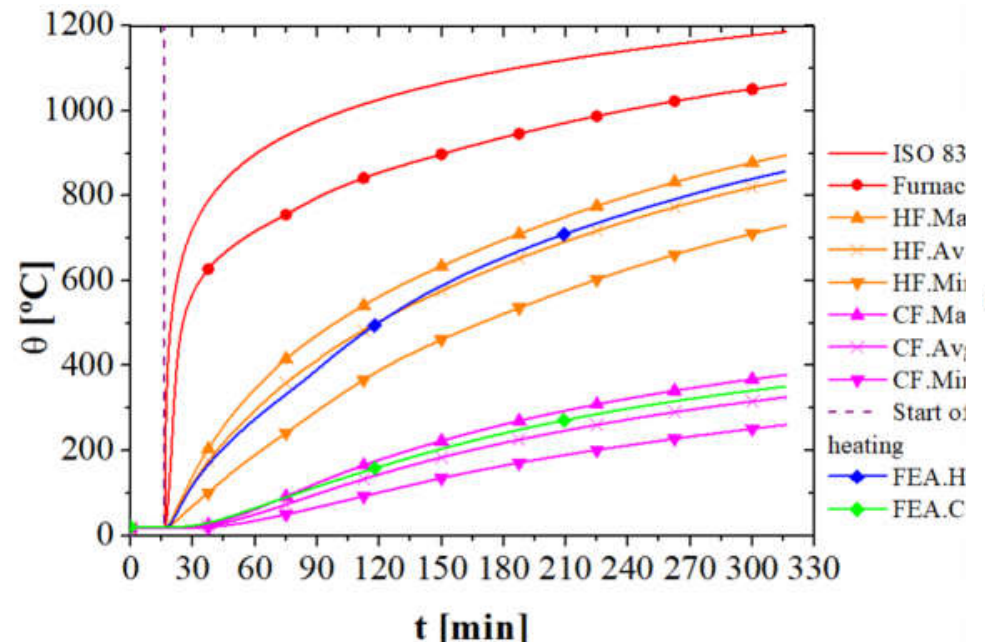

a)

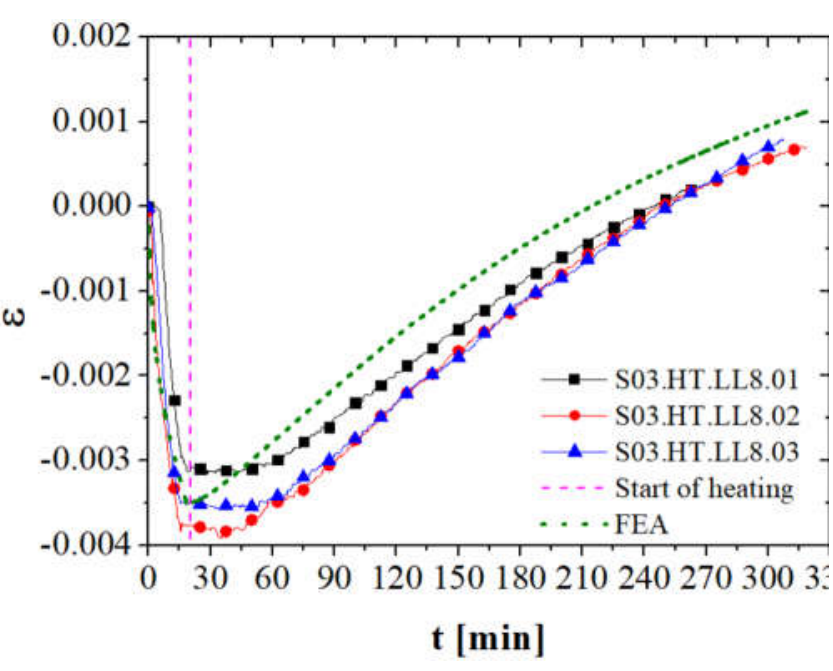

b)

Figure 28 - Validation of numerical model - test series S03.HT.LL8: a) Temperatures; b) In-plane strains

\subsection{Test series S04.HT.RTE}

Figure 29 shows the comparison of the in-plane strains and stresses obtained in the experimental and numerical tests for test series S04.HT.RTE. The curves of the FEA analysis fit closely with the experimental ones. This good agreement between the experimental and numerical results once more ensures the validity of the developed finite element model. There is a difference in the numerical and experimental reactions (Figure $29 \mathrm{~b}$ ), between 20 and 45 minutes. In the experimental curves it is possible to observe a plateau between 20 
and 45 minutes before the reaction force starts increasing. This may have been caused by slightly pressure drop in the hydraulic system.

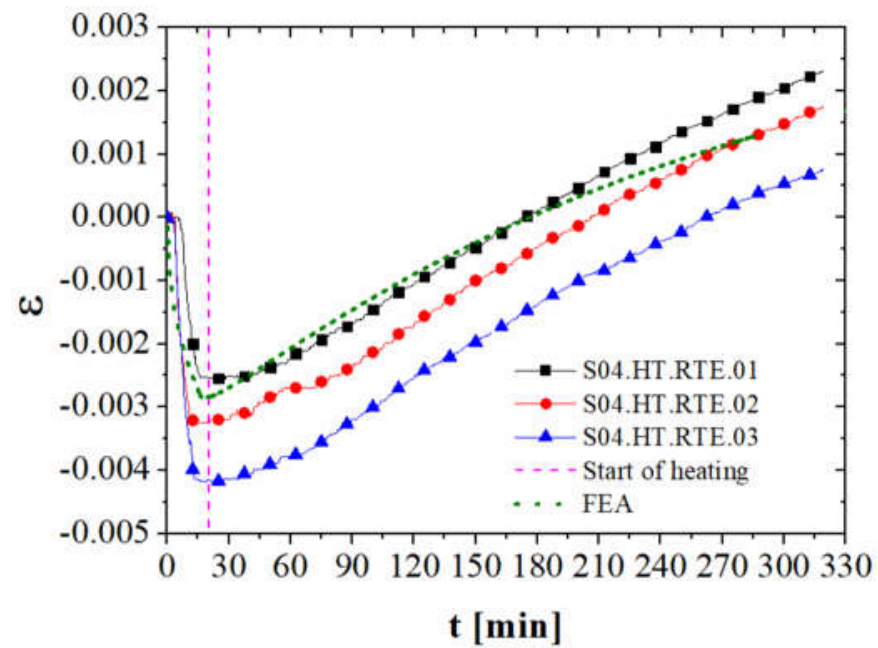

a)

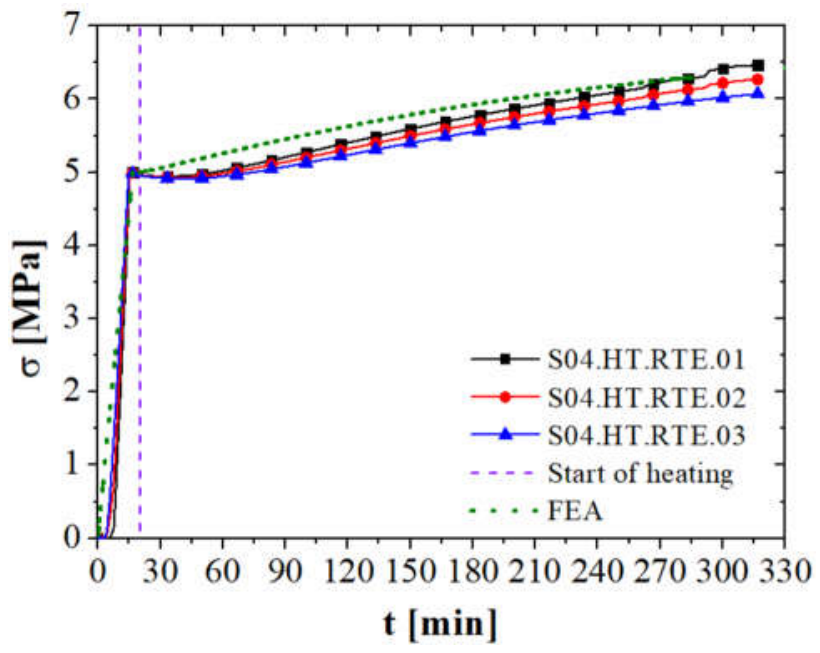

b)

Figure 29 - Validation of numerical model - test series S04.HT.RTE: a) In-plane strains; b) Stresses

\subsection{Test series S05.HT.LL10}

Figure 30a shows the comparison of temperatures obtained in the experimental and numerical tests for test series S05.HT.LL10. As in the previous heat transfer analyses, the temperatures predicted in the exposed and non-exposed face by the FEA model are in good agreement with the average of the measured temperature. The smaller thickness of the specimens tested in this series $(100 \mathrm{~mm})$ results in a faster temperature evolution both in exposed and non-exposed face, when compared to test series S03.HT.LL08 and S04.HT.RTE (140 $\mathrm{mm}$ thickness). The comparison of the in-plane strains obtained experimentally and numerically are presented in Figure 30b. The compressive stress of $10 \mathrm{MPa}$ is applied during the first 20 minutes of the test, and the average displacements measured in the tests and predicted by the numerical model are in good agreement. At 20 minutes the furnace is turned on and the temperatures starts to rise. Therefore, a positive strain rate is observed in the specimen. At the beginning of the heating, the strain rate developed in the numerical model is slightly higher than observed in the numerical model. A good agreement in temperatures and displacements was observed between the experimental and numerical results, for all stages of the test. 


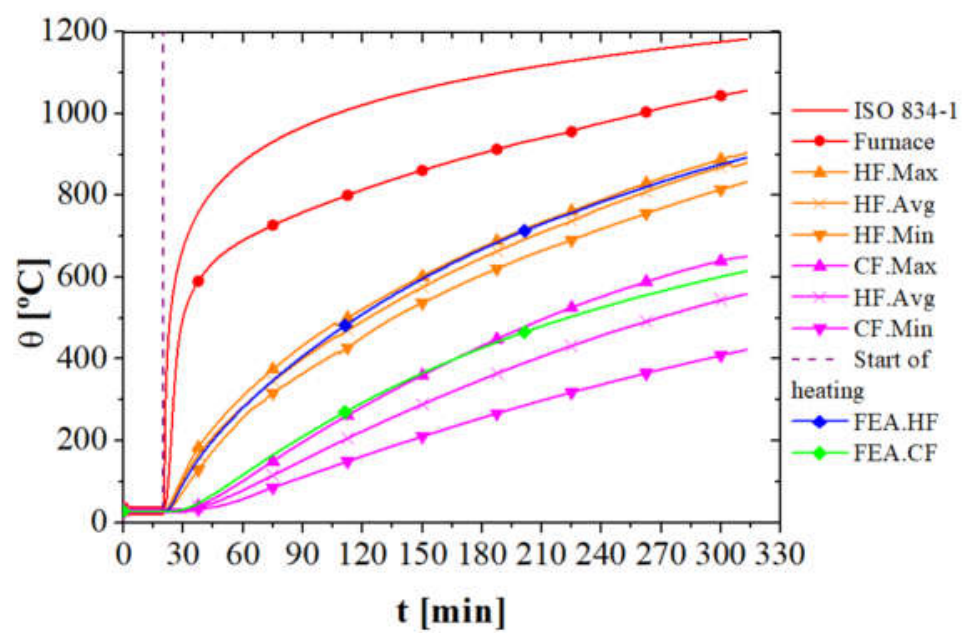

a)

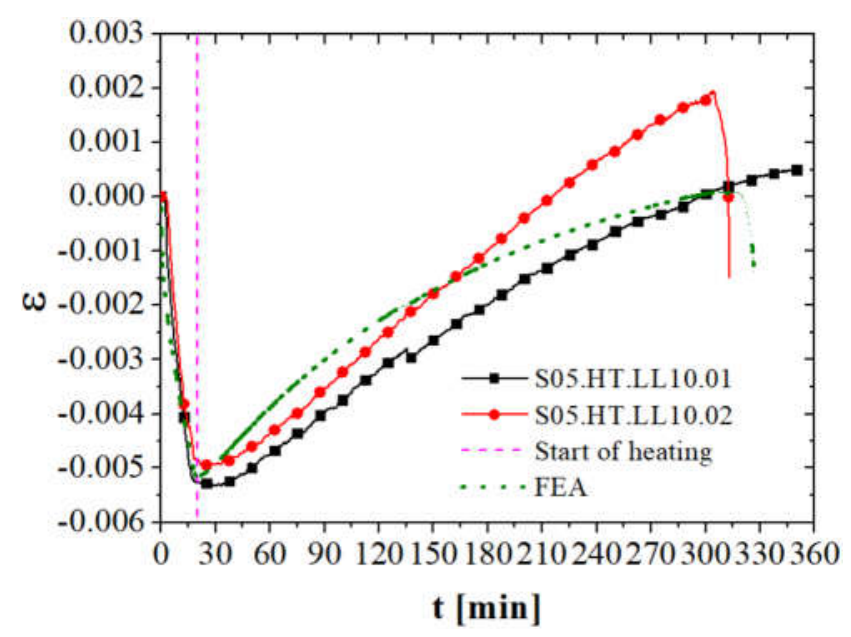

b)

Figure 30 - Validation of the numerical model - test series S05.HT.LL10: a) Temperatures; b) In-plane strains

In case of specimen S05.HT.LL10.02, failure of the wall was observed. The thermal gradient through the thickness of the sample led to the thermal bowing of the wall, therefore, significant out of plane displacements were observed in the sample, with failure ultimately. Figure 31 a presents the comparison of the out-of-plane displacements $\left(\mathrm{d}_{\mathrm{op}}\right)$ obtained experimentally and numerically. Figure $31 \mathrm{~b}$ illustrate the out-of-plane displacement fields.

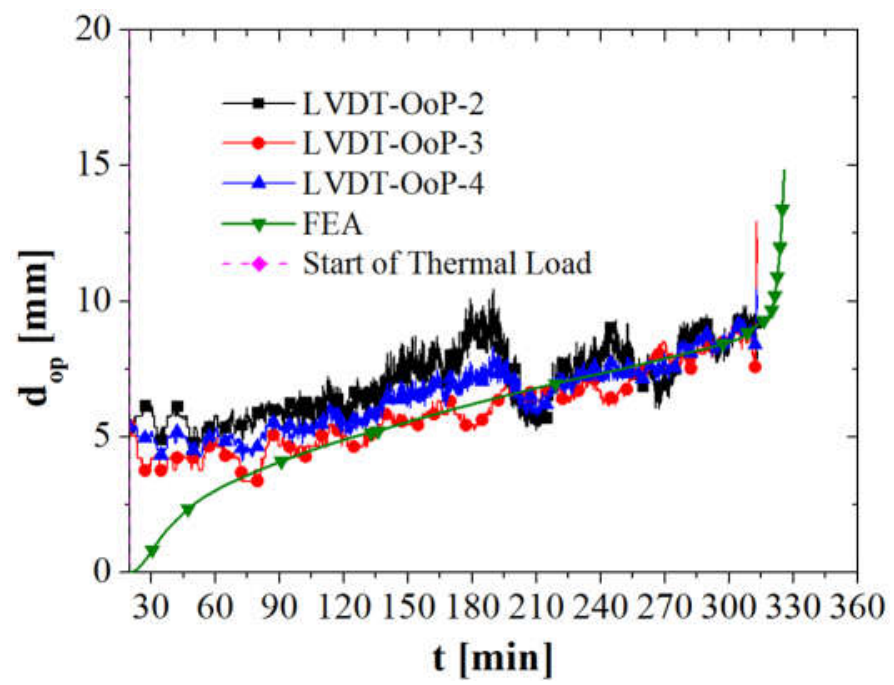

a)

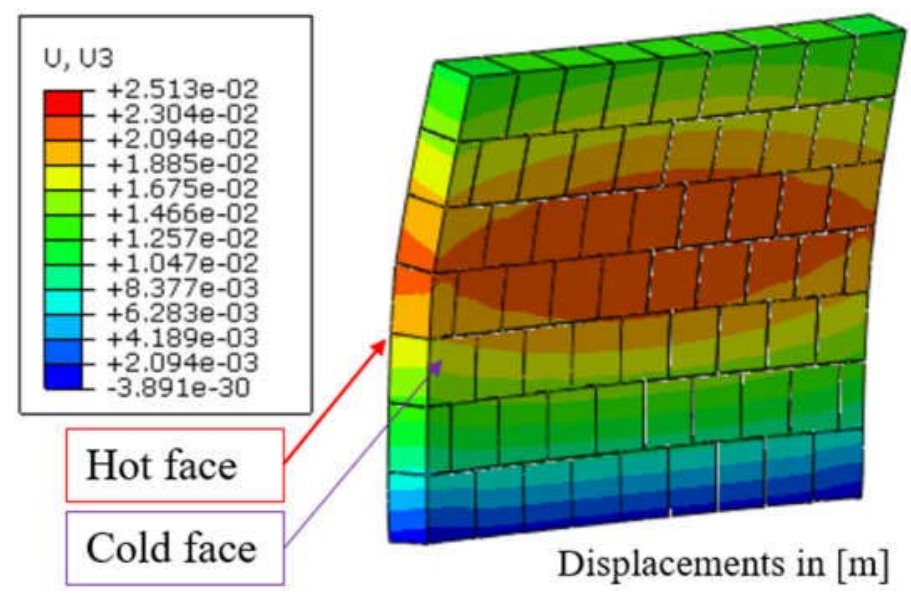

Displacements in [m]

Figure 31 - Out-of-plane displacements: a) Comparison between numerical and experimental results, b) Out-of-plane displacements fields at 300 minutes

Figure 32 shows the stresses in vertical direction and the plastic strains developed in the wall. The results clearly show that the effects of load eccentricity caused by the thermal bowing of the wall led to a significant 
stress concentration in the cold face of the wall. Significant plastic strains are developed in this face, and the crushing of the bricks are observed. Thus, the developed model is able to represent all stages of the test, including the effects of thermal elongation on the masonry specimens and the failure of the wall caused by eccentricity due to thermal bowing, as shown in Figure 31 and Figure 32.

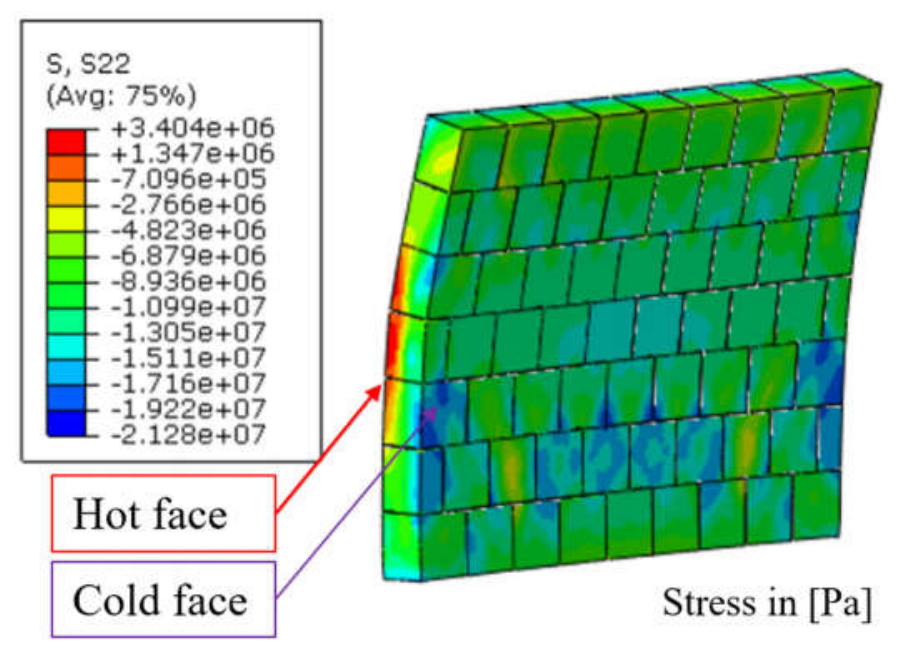

a)

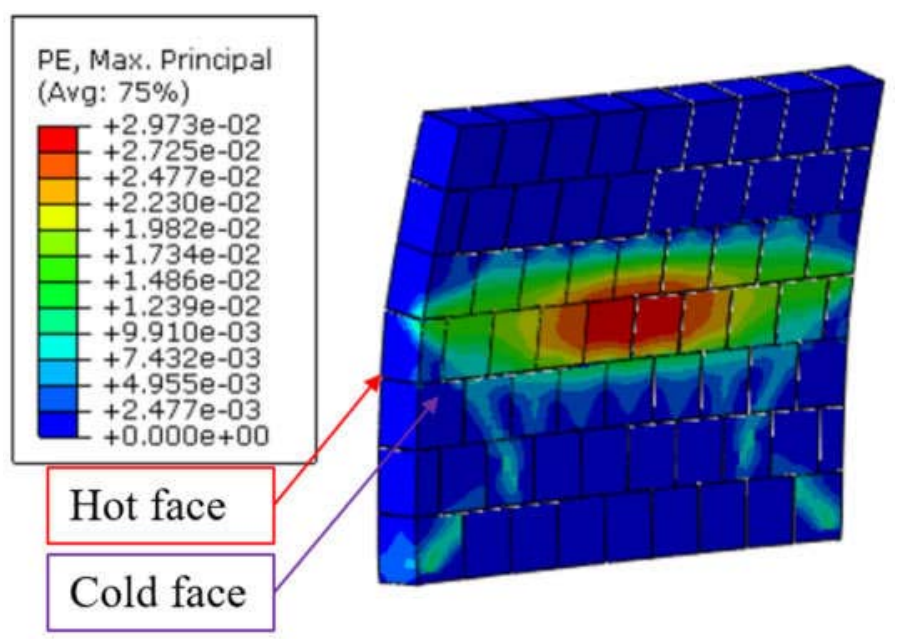

b)

Figure 32 - Numerical predictions by the end of the tests: a) Vertical stresses; b) Plastic strains

\subsection{Analysis and discussion}

As observed in the experimental results and reported in the literature review, refractory materials have a highly heterogeneous behaviour. As expected, some scatter was found in the results of the present experimental campaign using dry stacked masonry, including the in-plane stiffness, temperatures distributions and reaction forces, as presented in section 3. Nevertheless, the scatter obtained in the experimental results is acceptable, given the variability in the material and in the geometry.

The numerical analysis presented good agreement with the experimental results. The thermomechanical characterization of the alumina spinel brick, including the evaluation of the material compressive strength [33], tensile strength [34], Young's modulus [34], thermal elongation [34] and joint behaviour [33] led to reliable data base that may be used to analyse and design refractory linings with this material. The material 
properties were experimentally assessed in previous works and validated against the experimental results presented in this study.

The CDP model was suitable to represent the mechanical behaviour of refractory masonries at ambient and intermediate temperatures (where creep effects are not significant). Nevertheless, due to the service conditions of refractory linings, where the temperatures in services may reach up to $1650{ }^{\circ} \mathrm{C}$, further studies should be carried out to include the creep behaviour. Coupling of the CDP model with some creep law, such as NortonBailey, is required to represent the mechanical behaviour of refractory masonry under a large range of temperatures, from ambient up to the service temperatures.

The micro-modelling technique adopted led to good predictions of the behaviour of masonry at ambient and high temperatures. This technique requires more computational resources when compared to the macromodelling and homogenization techniques. However, it has greater accuracy and it gives detailed information on the joint's behaviour. The use of homogenization techniques may overcome the drawback of the micromodelling technique, being more suitable for modelling refractory linings at industrial scale.

The formulation recommended by Thanoon et al [13] presents the evolution of the compressive stresses in the wall in terms of joint closure. The formulation was proven to be suitable to model the normal behaviour of dry-joints presenting good results for the loading stage of the tests. However, this formulation may not be used to represent the residual strains on the unloading stage and, consequently, different models must be used to represent the loading and unloading of masonry.

\section{Conclusions}

An experimental and numerical investigation in the thermomechanical behaviour of refractory dry-stacked masonry walls under uniaxial compression at ambient and high temperatures was carried out. The experimental programme comprised fourteen tests, six at ambient and eight at high temperatures. Moreover, numerical simulations were also performed using the finite element software Abaqus [43]. 
In the experimental programme, test series S01.AT.LBC was used to assess the loadbearing capacity of the wall. Three different stages were found on the behaviour: $i$ ) joint closure; ii) linear behaviour; iii) plastic behaviour and failure. The effects of the bricks' height imperfections on the uneven stress distribution and on the flow of internal forces were detailed and discussed. Test series S02.AT.CIC aimed to evaluate the behaviour of the walls under cyclic loading. The crushing of initial non-plane surfaces caused by the mechanical loading were evidenced by the residual strains obtained after each load cycle. This effect results in the increase of the contact area between the bricks and consequently, larger wall's Young's modulus. Test series S03.HT.LL8, S04.HT.RTE and S05.HT.LL10 were tested at high temperatures. In test series S03.HT.LL8, the specimens were tested under a constant load level of $8 \mathrm{MPa}$. Test series S04.HT.RTE was tested with restrained thermal elongation. In spite of the small load level applied to test series S03.HT.LL8 and S04.HT.RTE, cracks were found in the wall by the end of the tests, caused by the non-uniformity on load and support conditions of the bricks. Moreover, some rigid body motion of the bricks was observed in the surrounding area of bricks with cracks, resulting in head joint openings. In test series S05.HT.LL10 the specimens were tested under a load level of $10 \mathrm{MPa}$ and the wall was led to failure at high temperatures. The eccentricities in the wall caused by the thermal bowing led to failure of the wall.

The good agreement between the experimental and numerical results shows the validity of the numerical models and demonstrate that the finite element analysis is a reliable tool to predict with accuracy the behaviour of refractory masonry, under the conditions used in these tests. The CDP model proved to be suitable for representing the mechanical behaviour of refractory masonry at ambient and intermediate temperatures, in which creep effects are not significant. The micro-modelling led to good predictions of the behaviour of masonry in the tested range of temperatures. The sequential coupled analysis led to a reduction on the required computation resources to perform the numerical analysis, when compared to the coupled thermal-structural analysis.

Since the thermal loads used in this study, are still far from the temperatures in service for these elements, caution is advised when using and extrapolating the present results. Additional studies, both experimental and numerical, are required to obtain a broader understanding of the behaviour of such applications. Specially, 
additional tests at higher service temperatures, where it will be possible to investigate the behaviour of these elements under creep and relaxation, are of critical importance. Additionally, the coupling of the CDP model with creep models is needed, aiming to develop a model able to represent the behaviour of these materials from ambient temperature up to the high service temperatures, that may reach $1650^{\circ} \mathrm{C}$ for steel ladles. Further developments regarding homogenization techniques will allow the simulation of the thermomechanical behaviour of refractory linings of industrial applications, with better efficiency.

\section{Acknowledgements}

This work was supported by the funding scheme of the European Commission, Marie Skłodowska-Curie Actions Innovative Training Networks in the frame of the project ATHOR - Advanced THermomechanical multiscale mOdelling of Refractory linings 764987 Grant.

\section{Conflicts of Interest}

The authors declare no conflict of interest.

\section{References}

[1] J. Poirier and M. Rigaud. "Corrosion of Refractories: The Fundamentals". F.I.R.E Compendium Series. 2017,450 p.

[2] Khlifi, I. "Optimisation of optical methods for strain field measurements dedicated to the characterisation of the fracture behaviour of refractories: Application to magnesia based materials. Material chemistry". PhD Thesis, University of Limoges, 2019, 182 p.

[3] Allaoui, S.; Rekik, A.; Gasser, A., Blond, E.: Andreev, K. "Digital Image Correlation measurements of mortarless joint closure in refractory masonries”. Construction and Building Materials, vol. 162, 2018, pp. $334-344$ 
[4] Ramanenka, D.; Stjernberg, J.; Eriksson, K.; Jonsén, P. "Modeling of refractory brick furniture in rotarykiln using finite element approach". 11th World Congress on Computational Mechanics (WCCM XI), Barcelona - Spain, 2014, pp. 1199-1210

[5] Nguyen, T.; Blond, E.; Gasser, A.; Prietl; T. "Mechanical homogenisation of masonry wall without mortar”. European Journal of Mechanics - A/Solids. vol. 28, Issue 3, 2009, pp. 535-544.

[6] Gasser, A.; Terny-Rebeyrotte, K.; Boisse, P. "Modelling of joint effects on refractory lining behaviour". Journal of Materials: Design and Applications, vol. 218, issue 1, 2004, pp.19-28.

[7] Shubin, V. "Mechanical effects on the lining of rotary cement kilns" Refractories and Industrial Ceramics, vol. $42, n^{\circ} 5-6,2001$, pp. 245-250.

[8] Stueckelschweiger, M.; Gruber, D.; Jin, S.; Harmuth, H. "Creep testing of carbon containing refractories under reducing conditions”. Ceramics International, vol. 45, Issue 8, 2019, pp. 9776-9781

[9] Samadi, S.; Jin, S.; Gruber, D.; Harmuth, H.; Schachneret, S. "Statistical study of compressive creep parameters of an alumina spinel refractory". Ceramics International, vol. 46, Issue 10-A, 2020, pp. $14662-$ 14668

[10] Teixeira, L.; Samadi, S.; Gillibert, J.; Jin S.; Sayet, T.; Gruber, D.; Blond, E. "Experimental Investigation of the Tension and Compression Creep Behavior of Alumina-Spinel Refractories at High Temperatures". Ceramics, vol.3(3), 2020, pp. 372-383

[11] Ngapeya, G.; Waldmann, D.; Scholzen, F. "Impact of the height imperfections of masonry blocks on the load bearing capacity of dry-stack masonry walls". Construction and Building Materials vol. 165, 2018, pp. $898-913$

[12] Zahra, T.; Dhanasekar, M."Characterisation and strategies for mitigation of the contact surface unevenness in dry-stack masonry". Construction and Building Materials, vol. 169, 2018, pp 612-628

[13] Thanoon, W.; Alwathaf, A.; Noorzaei, J.; Jaafar, M.; Abdulkadir, M. "Finite element analysis of interlocking mortarless hollow block masonry prism". Computers and Structures, vol. 86, 2008, pp. 520-528 [14] Andreev, K.; Sinnema, S.; Rekik, A.; Allaoui, S.; Blond, E.; Gasser, A. "Compressive behaviour of dry joints in refractory ceramic masonry". Construction and Building Materials, vol. 34, 2012, pp. 402-408 
[15] Oliveira, R.; Rodrigues, J.; Pereira, J.; Lourenço, P.; Lopes, R. "Experimental and numerical analysis on the structural fire behaviour of three-cell hollowed concrete masonry walls". Engineering Structures, Available online 14 November 2020, 111439, In Press

[16] Kumar P., Kodur V.K.R. (2017), Modelling the behaviour of load bearing concrete walls under fire exposure. Construction and Building Materials, 154, pp. 993-1003

[17] Andreini, M., Caciolai, M., La Mendola, S., Mazziotti, L., Sassu, M. (2015), Mechanical behaviour of masonry materials at high temperatures". Fire and Materials, 39, pp. 41-57.

[18] Nguyen T. D., Meftah F. (2012), Behaviour of clay hollow-brick masonry walls during fire. Part 1: Experimental analysis. Fire Safety Journal, 52, pp 55-64

[19] Nguyen T.D., Meftah F. (2014), Behaviour of hollow clay brick masonry walls during fire. Part 2: 3D finite element modelling and spalling assessment. Fire Safety Journal, 66, pp. 35-45

[20] Nadjai A., O'Garra M., Ali F. A., Laverty D. (2003), A numerical model for the behaviour of masonry under elevated temperatures. Fire and Materials, 27-4, pp. 163-182

[21] Nadjai A., O'Garra M., Ali F. A., Laverty D. (2003), Finite element modelling of compartment masonry walls in fire. Computer and Structures 81, pp 1923-1930

[22] Al Nahhas, F, Ami Saada R, Bonnet G, Delmotte P. (2007), Resistance to fire of walls constituted by hollow blocks: Experiments and thermal modelling. Applied Thermal Engineering 27-1, pp 258-267

[23] Dhanasekar M., Chandrasekaran V., Grubits S. J. (1994), A numerical model for thermal bowing of masonry walls. 10th IB2MaC, pp. 1093-1102.

[24] O’Meagher A. J., Bennetts I. D. (1991), Modelling of Concrete Walls in Fire. Fire Safety Journal, 17, pp $315-335$

[25] Shields, TJ. O’Connor, DJ. Silcock, GWH. Donegan, HA. (1988), Thermal bowing of a model brickwork panel, Proceedings of 8th International Brick/Block Masonry Conference, Dublin, Vol. 2, pp. 846-856.

[26] Lawrence S., Gnanakrishnan N. (1987), The Fire Resistance of Masonry Walls - An Overview. First National Structural Engineering Conference, Melbourne, Australia, pp 431-437

[27] Byrne S. (1979), Fire resistance of load-bearing masonry walls. Fire Technology 15-3, pp 180-188. 
[28] T. Prietl, “Ermittlung materialspezifischer Kennwerte von feuerfesten Werkstoffen und Zustellungen unter uni- und biaxialen Lastbedingungen für die Nichteisenmetallindustrie," PhD Thesis, University of Leoben, 2006, 192 pages.

[29] Prietl, T.; Zach, O.; Studnicka, H. "The evaluation of refractory linings thermomechanical properties". Erzmetall - World of metallurgy, 59, 2006, pp. 127-132

[30] Ali M.; Sayet, T.; Gasser, A. and Blond, E. "Thermomechanical Modelling of Refractory Mortarless Masonry Wall Subjected to Biaxial Compression". Unified International Technical Conference of Refractories, Yokohama - Japan, 2019, pp. 205-208

[31] EN ISO 12677:2011. Chemical analysis of refractory products by X-ray fluorescence (XRF). Fused castbead method. European Committee for Standardisation, Brussels, Belgium.

[32] EN 993-1 Methods of test for dense shaped refractory products. Determination of bulk density, apparent porosity and true porosity. European Committee for Standardisation, Brussels, Belgium.

[33] Oliveira, R.; Rodrigues J. P.; Pereira, J. M. "The Characterization of joint Behaviour in Mortarless Refractory Masonry”. In Proceedings of the Unified International Technical Conference of Refractories, Yokohama, Japan, 2019, pp. 612-614

[34] Kaczmarek, R.; Dupre, J.C.; Doumalin, P.; Pop, I.O.; Teixeira, L.B.; Gillibert, J.; Blond E. and Huger, M. "Thermomechanical behaviour of an alumina spinel refractory for steel ladle applications". Unified International Technical Conference of Refractories, Yokohama - Japan, 2019, pp. 422-425

[35] Samadi, S.; Jin, S.; Gruber, D.; Harmuth, H. "Creep parameter determination of a shaped aluina spinel refractory using statistical analysis. International Coloquium of Refractories, Aachen - Germany, 2020, pp [36] Teixeira, L.; Gillibert, J.; Blond, E.; Sayet, T. “Creep characterization of refractory materials at high temperatures using the Integrated Digital Image Correlation". Unified International Technical Conference of Refractories, Yokohama - Japan, 2019, pp. 899-902

[37] ISO 834-1 (1999), Fire resistance tests - elements of building construction, Part 1: general requirements. International Organization for Standardization, Geneva, Switzerland. 
[38] Belrhiti, Y.; Dupre, J.C.; Pop, O.; Germaneau, A.; Doumalin, P.; Huger, M.; Chotar, T. “Combination of Brazilian test and digital image correlation for mechanical characterization of refractory materials". Journal of the European Ceramic Society, vol. 37, 2017, pp. 2285-2293

[39] Dupré, J.C.; Doumalin, P.; Belrhiti, Y.; Khlifi, I.; Pop, O.; Huger, M. "Detection of cracks in refractory materials by an enhanced digital image correlation technique”. Journal of Materials Science, vol. 53, 2018, pp. $977-993$

[40] Lourenço P. B. (2009) Recent advances in masonry modelling: micromodelling and homogenization. In: Multiscale Modelling in Solid Mechanics, pp. 251-294.

[41] Pereira J. M., Campos J., Lourenço P.B. (2015) Masonry infill walls under blast loading using confined underwater blast wave generators (WBWG). Engineering Structures, 92, pp. 69-83

[42] Ali, M.; Sayet, T.; Gasser, A.; Blond, E. "Transient Thermo-Mechanical Analysis of Steel Ladle Refractory Linings Using Mechanical Homogenization Approach”. Ceramics, 2020, vol. 2, pp 171-188

[43] Abaqus User Manual (2010), Dassault Systems Simulia Corporation, USA.

[44] EN 1996-1-2 (2005), Eurocode 6 - Design of masonry structures, Part 1-2: General rules Structural Fire Design, European Committee for Standardisation, Brussels, Belgium.

[46] Lubliner J., Oliver J., Oller S. and Onate E. (1989), A plastic-damage model for concrete. Int. J. Solids Struct.,25(3), pp 299-329.

[46] Lee J. and Fenves G. L. (1998), Plastic-damage model for cyclic loading of concrete structures. J. Eng. Mech. 124 (8), pp 892-900. 